Florida International University FIU Digital Commons

11-18-2002

\title{
The impact of the Florida state-mandated basic skills exit test at Miami-Dade Community College
}

Joanne Bashford

Florida International University

DOI: $10.25148 /$ etd.FI14050453

Follow this and additional works at: https://digitalcommons.fiu.edu/etd

Part of the Community College Education Administration Commons

\section{Recommended Citation}

Bashford, Joanne, "The impact of the Florida state-mandated basic skills exit test at Miami-Dade Community College" (2002). FIU Electronic Theses and Dissertations. 1430.

https://digitalcommons.fiu.edu/etd/1430 


\section{FLORIDA INTERNATIONAL UNIVERSITY}

Miami, Florida

THE IMPACT OF THE FLORIDA STATE-MANDATED

BASIC SKILLS EXIT TEST AT MIAMI-DADE COMMUNITY COLLEGE

A dissertation submitted in partial fulfillment of the

requirements for the degree of

DOCTOR OF EDUCATION

in

EDUCATIONAL ADMINISTRATION AND SUPERVISION

by

Joanne Bashford

2002 
To: Dean Linda Blanton

College of Education

This dissertation, written by Joanne Bashford, and entitled The Impact of the Florida State-Mandated Basic Skills Exit Test at Miami-Dade Community College, having been approved in respect to style and intellectual content, is referred to you for judgment.

We have read this dissertation and recommend that it be approved.

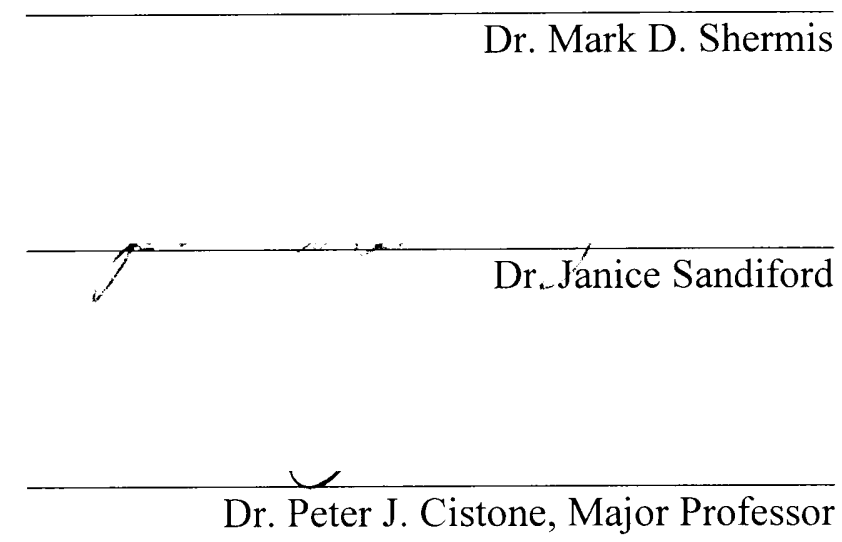

Date of Defense: November 18, 2002

The dissertation of Joanne Bashford is approved.

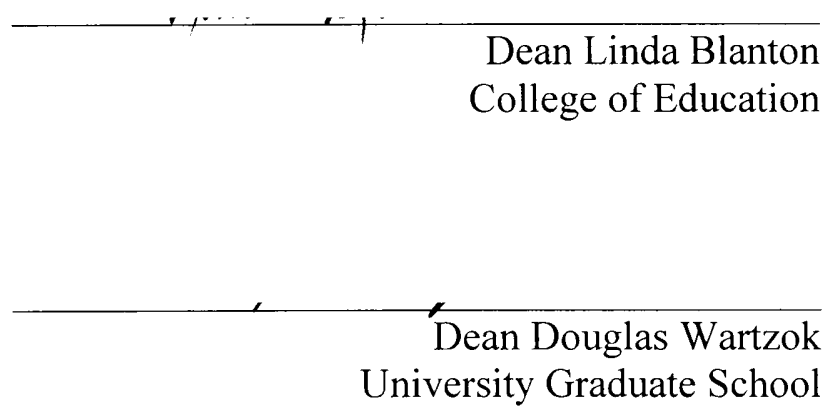

Florida International University, 2002 


\section{ACKNOWLEDGMENTS}

I would like to thank the members of my committee for their support and guidance during the conduct of this study. I am particularly indebted to my Major Professor, Peter J. Cistone, for his encouragement, insights, and ability to keep me on task. He always maintained a positive, "can do" attitude that helped to keep me motivated. All of my committee members were there when I needed them, ready to offer suggestions and talk through obstacles. I truly appreciate their willingness to share their knowledge and experience. 


\section{ABSTRACT OF THE DISSERTATION \\ THE IMPACT OF THE FLORIDA STATE-MANDATED \\ BASIC SKILLS EXIT TEST AT MIAMI-DADE COMMUNITY COLLEGE \\ by}

Joanne Bashford

Florida International University, 2002

Miami, Florida

Professor Peter J. Cistone, Major Professor

The purpose of this study was to explore the impact of the Florida Statemandated Basic Skills Exit Tests (BSET) on the effectiveness of remedial instruction programs to adequately serve the academically underprepared student population. The primary research question concerned whether the introduction of the BSET has resulted in remedial completers who are better prepared for college-level coursework.

This study consisted of an ex post facto research design to examine the impact of the BSET on student readiness for subsequent college-level coursework at MiamiDade Community College. Two way analysis of variance was used to compare the performance of remedial and college-ready students before and after the introduction of the BSET requirement. Chi-square analysis was used to explore changes in the proportion of students completing and passing remedial courses. Finally, correlation analysis was used to explore the utility of the BSET in predicting subsequent collegelevel course performance. Differences based on subject area and race/ethnicity were explored. 
The introduction of the BSET did not improve the performance of remedial completers in subsequent college-level courses in any of the subject areas. The BSET did have a negative impact on the success rate of students in remedial reading and mathematics courses. There was a significant decrease in minority students' likelihood of passing remedial reading and mathematics courses after the BSET was introduced. The reliability of the BSET is unacceptably low for all subject areas, based on estimates derived from administrations at M-DCC. Nevertheless, there was a significant positive relationship between BSET score and grade point average in subsequent college-level courses. This relationship varied by subject area and ethnicity, with the BSET reading score having no relationship with subsequent course performance for Black non-Hispanic students.

The BSET had no discernable positive effect on remedial student performance in subsequent college-level courses. In other words, the BSET has not enhanced the effectiveness of the remedial programs to prepare students for later coursework at MDCC. The BSET had a negative impact on the progress and success of students in remedial reading and mathematics. 


\section{TABLE OF CONTENTS}

CHAPTER

PAGE

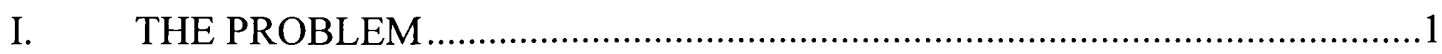

Background of the Problem .........................................................................

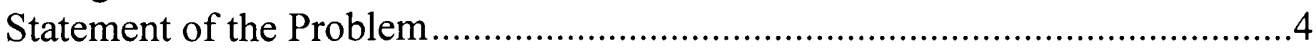

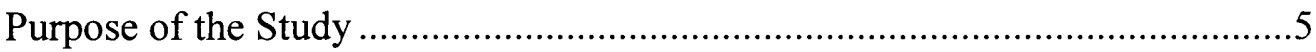

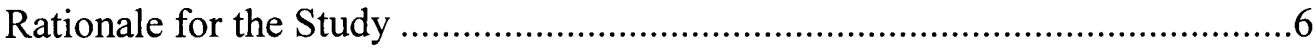

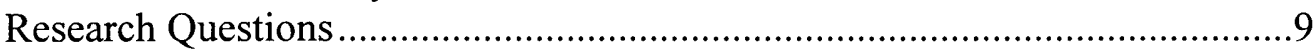

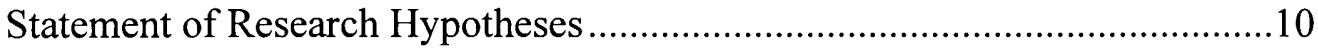

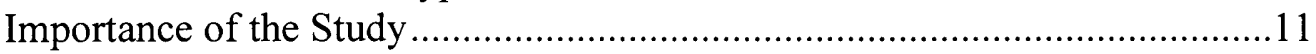

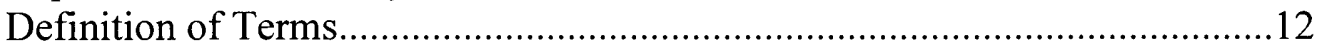

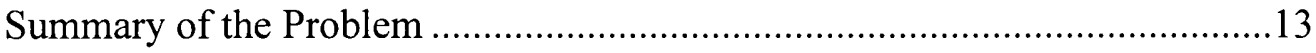

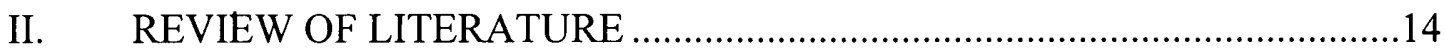

High-Stakes Tests for Education Reform and Accountability.........................15

Public Policy and the Use of Tests in Florida.............................................18

The Consequences of High-Stakes Testing .....................................................24

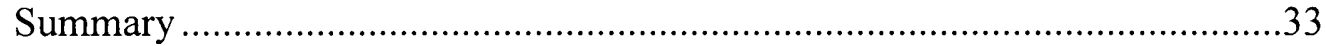

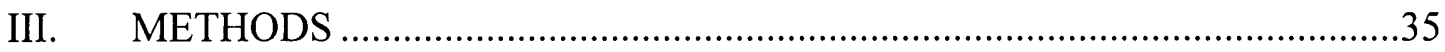

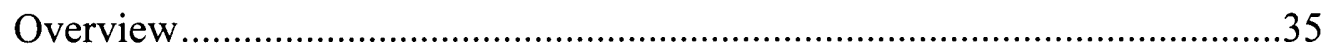

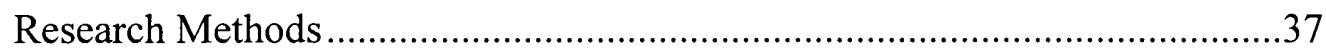

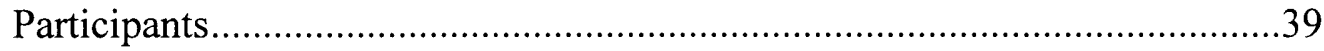

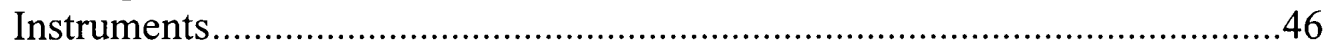

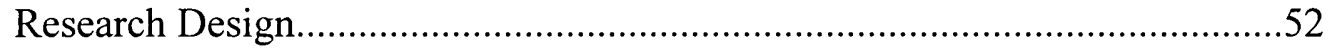

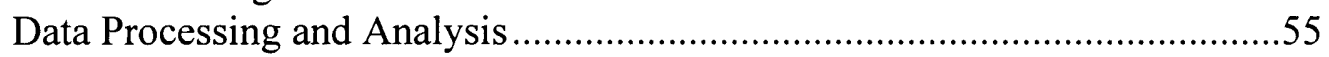

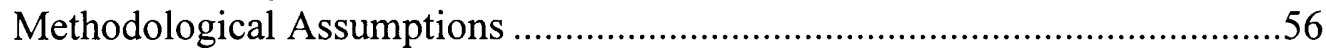

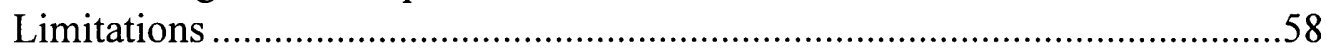

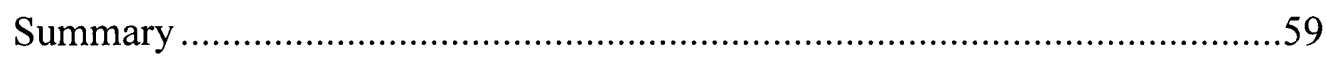

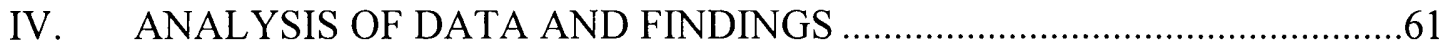

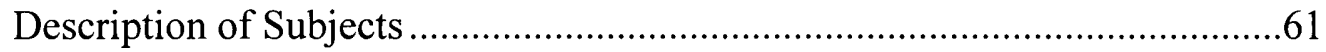

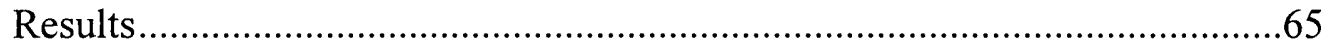

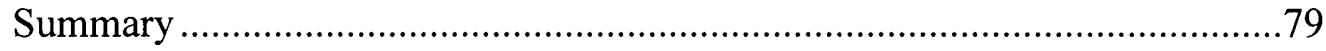

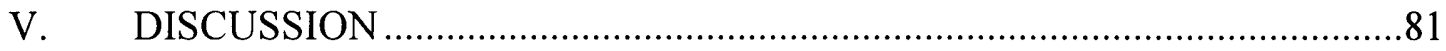

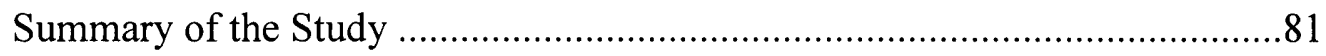

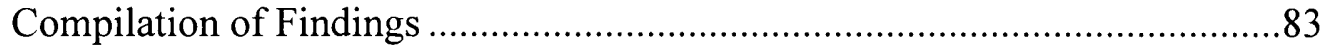

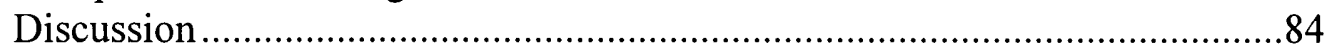

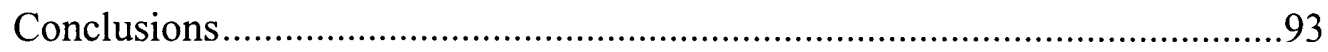

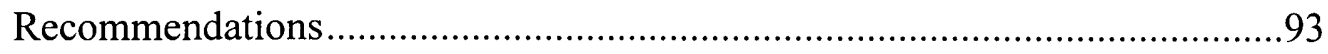

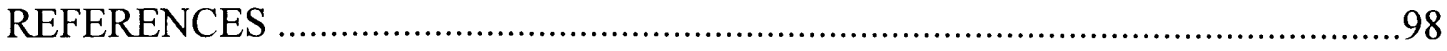




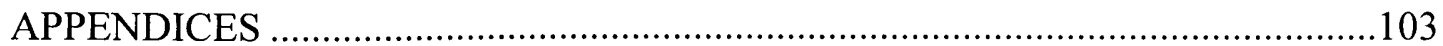

VITA 


\section{LIST OF TABLES}

TABLE

1. Number of Students Included in Analysis of Performance in Subsequent College-Level Coursework

2. Number of Students Included in Analysis of Remedial Course Completion and Success by Subject and Race/ethnicity

3. Students Included in BSET/Course Grade Correlation ...............................64

4. Analysis of Variance for Reading Using Type III Sums of Squares ............66

5. Observed and Adjusted Sample Means for Reading …...............................66

6. Analysis of Variance for English Using Type III Sums of Squares .............68

7. Observed and Adjusted Sample Means for English by Group ....................68

8. Observed and Adjusted Sample Means for English by Ethnicity ................69

9. Analysis of Variance for Mathematics Using Type III Sums of Squares....69

10. Observed and Adjusted Sample Means for Mathematics .............................70

11. Reading Grade Distribution for Total Group...........................................72

12. Reading Grade Distribution for Black non-Hispanics ...............................72

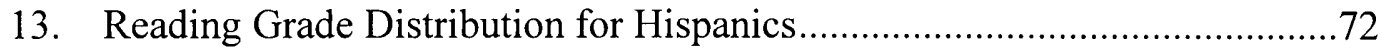

14. Reading Grade Distribution for White non-Hispanics...............................73

15. English Grade Distribution for Total Group ............................................73

16. English Grade Distribution for Black non-Hispanics ..............................74

17. English Grade Distribution for Hispanics ....................................................

18. English Grade Distribution for White non-Hispanics.................................74

19. Mathematics Grade Distribution for Total Group ......................................75

20. Mathematics Grade Distribution for Black non-Hispanics.........................76 
21. Mathematics Grade Distribution for Hispanics

22. Mathematics Grade Distribution for White non-Hispanics .76

23. Descriptives From Correlation Analysis by Subject Area .77

24. Correlations Between BSET Score and Grade by Subject Area and Race/ethnicity .78 


\section{CHAPTER I}

\section{THE PROBLEM}

As part of an ongoing effort to enhance the quality and accountability of remedial education in Florida, the 1997 Florida State Legislature passed legislation (the Postsecondary Education Act) amending Section 240.117 (4)(a), F.S., to require students to pass a standardized, institutionally developed exit test. This test was intended to certify that students had met basic computation and communications skills requirements for successful completion of the remedial curriculum and grant permission to progress to college-level courses. This high-stakes exit test came to be known as the Florida College Basic Skills Exit Test (BSET) and is the subject of this study.

\section{Background of the Problem}

Within the State of Florida and nationwide, considerable attention has been focused on remedial instruction at the college level in recent years. The debate has centered on whether students are receiving adequate instruction, achieving at a level that indicates readiness for college-level coursework, and whether remedial instruction at the college level is an appropriate use of state funds. Prior to the 1997 Florida Legislative Session, remediation at the community college level was estimated to cost the state as much as $\$ 55$ million annually (Staff of the Committee on Higher Education, 1996). The magnitude of the remedial problem in Florida is apparent as approximately 69 percent of first-time-in-college students statewide and about 83 percent of first-time-in-college students at M-DCC are determined to be academically underprepared for college-level coursework by placement tests. A disproportionate number of minority students are found in this group at M-DCC (Florida Community College System, 2000). 
Given the significant number of students beginning in remediation, there was concern about the potential for grade inflation in college-level courses leading to low student achievement and lax graduation standards (State Level Panel, 1984). The College Level Academic Skills Test (CLAST) was adopted in the early 1980's largely in response to these concerns. The CLAST was developed to "ensure that students have achieved the skills expected of them before they move from one level of education to the next" (College Level Academic Skills Project, 1983, p. 1). In other words, the test was intended to serve as a barrier to prevent students whose skills were considered inadequate for success in college-level courses from progressing to upper division coursework in the State University System (SUS).

The CLAST met with numerous criticisms including the lack of predictive validity and adverse impact on minority students (Einspruch, 1988; Garcia, 1995; Losak, 1992; Morris \& Belcher, 1990). In response to such criticism, alternative means of demonstrating adequate skill levels were introduced in 1995. That is, students were not required to pass the CLAST if they had at least a 2.5 grade point average in related English or mathematics courses, or scores earned on the ACT or SAT which were high enough to attest to college-level computation and communications skills. These alternatives to the CLAST raised concern again over grade inflation and generated interest in finding other ways to certify the preparation of students, including the BSET (Staff of the Committee on Higher Education, 1996).

If remedial programs are effective, students who successfully complete remediation should be adequately prepared for college-level courses. Indeed, State Accountability Reports indicate that students who needed and completed remedial 
instruction before transferring to the SUS performed almost as well as students who were considered 'college-ready' upon entry (Florida Community College System, 2000). The CLAST was one of the checks and balances ensuring that students would perform at that level.

With the introduction of the alternatives to the CLAST, however, there was concern about whether remedial students would continue to perform as well (Staff of the Committee on Higher Education, 1996). The BSET was viewed as a way to control the content of the remedial courses, ensure alignment of curriculum and objectives between remedial and college-level courses, and impose standards of mastery that should enhance student success in subsequent courses.

Several Florida State Accountability Measures assess the performance of remedial programs, but with conflicting purposes (Florida Community College System, 2000). The College Preparatory Completion Measure (Measure 4, Part 1) reports the number and percent of students who complete required remediation in a given subject area within two years. Incentive funds are allocated based on each college's performance on this measure. Other measures include the retention and success of college preparatory students (Measure 4 Part 2), CLAST performance of college preparatory students (Measure 5), and grade point average in the upper division following graduation and transfer to the State University System of college preparatory students, all compared to college-ready students (Measure 2). Although colleges are rewarded for facilitating the remedial course completion of students, they must ensure that the students who complete the remedial courses are adequately prepared for subsequent college-level courses. 
The implication of the BSET requirement for students, however, is clear as they must pass the test to progress to college-level work. The BSET is a high-stakes test for students. Failure to pass the test effectively ends students' freedom to pursue a college degree at a Florida community college. In the same way that the CLAST served as a barrier to students' progress, the BSET has the potential to impact students in a similar way. Therefore the appropriateness of using the BSET as a high-stakes exam and the impact of its use need to be examined carefully.

\section{Statement of the Problem}

The problem addressed by this study is the impact of the high-stakes, Florida State-mandated Basic Skills Exit Test on the effectiveness of remedial instruction programs at the college level. The impact of the exit tests, and the appropriateness of using the tests to make important decisions about access to college-level work need to be examined. This study also explored the potential positive effect of enhanced performance in subsequent college-level courses following the introduction of the exit test requirement, and assessed the potential negative effects of fewer students successfully completing the remedial programs, and possible disproportionate impact on minority students.

The Student Assessment Services Section of the Florida Department of Education has not yet conducted any studies at the state level to evaluate the impact of the BSET requirement on the effectiveness of remedial instruction. The State of Florida Legislature imposed this exit test requirement as a means to improve the accountability of the remedial programs at the community college level. The impact of this requirement on the quality of the programs and instruction received by students should be evaluated. 
The purpose of this study was to explore the impact of the Basic Skills Exit Tests on the effectiveness of remedial instruction programs to adequately serve the academically underprepared student population. By exploring the impact at Miami-Dade Community College, the study addressed the question of whether this state-mandated high-stakes examination improved the effectiveness of remedial programs and enhanced the success of students.

The impact of the exit test requirement on the quality of instruction and level of student learning was measured by examining the performance of students who successfully completed the remedial program in subsequent college-level coursework for each of the three subject areas of reading, English, and mathematics. The performance of students who successfully completed remedial instruction was also compared with that of 'college-ready' students in the college-level courses for each of the subject areas to determine if the exit test requirement had narrowed the gap in performance between the student groups. This comparison also served to control for other changes that may have occurred during this time period as such changes were assumed to have impacted remedial program completers and college-ready students alike. In addition, unintended negative consequences of the BSET requirement were explored by examining the number and percent of students completing required remediation to determine whether the requirement has acted as an undue barrier to completion. Potential disparate impact on minority students was also explored by examining the number and percent of minority students completing remediation before and after the BSET requirement. This research 
has provided evidence on the intended benefits and unintended consequences of using the Basic Skills Exit Test to make decisions about individual students.

Rationale for the Study

The State of Florida has often used examinations, particularly minimum competency examinations to certify the skill levels of students, encourage high achievement among students, and compare the performance of schools and postsecondary institutions. One of the early examinations in this tradition of testing, the Florida TwelfthGrade Test, was developed and used at the high school level to measure skill levels prior to high school graduation. This test was used in combination with high school performance for university admission decisions. The State of Florida stopped funding this examination program due to allegations of racial bias and discriminatory use of test results (McTarnaghan, 1987, p. 77).

The High School Competency Test was developed and implemented to certify, as the name implies, basic competency levels of high school students. Students needed to pass the examination at established cut score levels to be awarded a high school diploma. Florida was one of the first states to institute such a high school graduation test and was also one of the first states to face a significant legal challenge over the use of tests for this purpose. This case, Debra P. v. Turlington, is widely cited as a landmark case in the highstakes testing arena. Although the State of Florida prevailed in this case, several legal standards emerged which have shaped the implementation of high-stakes examinations. These standards include the need to establish curricular validity, the need for adequate notice of test requirements, and the need to ensure adequate opportunity to learn the objectives covered by the examination (Linn, 1998, p. 2-3). 
More recently, the State of Florida has developed and implemented a new K-12 examination program, the Florida Comprehensive Assessment Test (FCAT). This examination is aligned with the Sunshine State Standards, or state-wide learning objectives, and measures student reading, writing and math skills in Grades 3-10 to ensure minimum student achievement and compare the performance of schools (Florida Department of Education, 2001). The tenth grade version of the FCAT is currently used to ensure adequate skills for high school graduation and replaced the High School Competency Test.

At the postsecondary level, the State of Florida introduced the College Level Academic Skills Test (discussed previously) to measure State defined college-level basic skills in reading, English language, essay writing, and mathematics. The most recent addition to this State testing tradition at the postsecondary level is the Basic Skills Exit Test (BSET), which is the subject of this research. Numerous research studies have been conducted on the state-wide testing programs that preceded the BSET (Garcia, 1995; Griffin \& Heindorn, 1996; Losak \& Einspruch, 1989; McTarnaghan, 1990; Wright, 1992), but none have been conducted on the BSET to date. This study of the BSET contributes to this line of inquiry into the impact and effectiveness of these high-stakes state-wide testing programs, and is particularly timely in light of recent federal mandates for national educational testing programs.

Coleman (2000) identified several questions that should be answered about highstakes testing programs. First, and perhaps foremost, the educational purpose of the test should be clearly identified, followed by assessment of how well the testing program accomplishes that purpose. In addition, consequences of the testing program need to be 
identified and weighed against the overall purpose of the examination and its effectiveness in meeting its objectives.

While there is evidence that curriculum based exit examinations increase student achievement (Bishop, 1998; Linn, 2000; Winfield, 1990), there is also evidence suggesting that this achievement does not generalize to other examinations or educational settings (Haertel, 1999; Klein, Hamilton, McCaffrey, \& Stecher, 2000). There are also studies that seem to show that high-stakes testing programs can have negative consequences including 'teaching to the test' which may reduce the curriculum to test preparation and inflate test scores (Heubert \& Hauser, 1999; Linn, 2000.)

Given that remedial programs are designed to provide students with adequate skills to succeed in college-level coursework, the introduction of an exit test should have a positive impact on subsequent coursework if the students' achievement in basic skills increased and appropriate levels of mastery were defined and accurately measured. Imposing objective standards for exiting the remedial courses that reflect mastery of the course competencies should ensure that students are prepared for subsequent collegelevel course(s). If minimum competency exit tests have a positive impact on the quality of remedial programs, student success in subsequent college-level courses should increase after the exit test requirement is implemented. Alternatively, if the exit tests result in 'teaching to the test' without commensurate increases in student learning, then student success in subsequent courses would not be enhanced as the test scores would not reflect a better, more thorough understanding of the subject.

Heubert and Hauser (1999) suggest three principal criteria for determining appropriate test use: a) measurement validity (Does the test accurately measure 
knowledge in the content area and is it valid for the specific purpose for which it is used?); b) attribution of cause (Is instruction the 'cause' of student performance on the test or are other non-instructional factors contributing?); and c) effectiveness of treatment (Do scores lead to decisions or consequences that are beneficial to the students?) This research was guided by these criteria for evaluating the use of high-stakes tests.

\section{Research Questions}

The following research questions were explored in this study:

1. To what extent has the state-mandated BSET improved college readiness of students at Miami-Dade Community College as measured by differences in GPA in first college-level courses before and after introduction of the BSET requirement for students who completed remedial coursework?

2. To what extent has the state-mandated BSET improved college readiness of students at Miami-Dade Community College as measured by differences in performance of remedial coursework completers compared with college-ready students before and after the introduction of the BSET (Is there a performance gap between remedial and college-ready students after the BSET)?

3. To what extent has the BSET affected remedial course completion and success rates?

4. Is there a relationship between BSET score and subsequent performance in college-level courses at Miami-Dade Community College? 
5. To what extent do these relationships vary by subject area and race/ethnicity?

\section{Statement of Research Hypotheses}

The research hypotheses to be explored in this study are as follows:

1. Students who completed remedial instruction after the introduction of the BSET requirement will have significantly higher grade point averages in college-level courses when compared with students who completed prior to the requirement for each of the subject areas of reading, English, and mathematics.

2. There will be no significant difference in grade point average in collegelevel courses for students who completed remedial instruction after the introduction of the BSET requirement when compared with college-ready students for each of the subject areas of reading, English, and mathematics.

3. There will be a significant relationship between remedial course completion and success rate and the BSET requirement.

4. There will a significant relationship between remedial course completion and success rate and the BSET requirement for minority students.

5. There will be a significant relationship between BSET score and collegelevel course GPA.

6. There will be a significant relationship between BSET score and collegelevel course GPA for minority students. 
Importance of the Study

The State of Florida has a history of proactive establishment of educational standards to ensure quality education in state funded community colleges. Testing programs have frequently been used by policy makers in Florida in the pursuit of these goals (e.g. the CLAST). However, little is known about the impact of the most recent testing program, the Florida College Basic Skills Exit Test (BSET), on the quality of remedial programs or on individual students.

This study was designed to explore the positive effects and potential negative consequences of the BSET on the outcomes of remedial education. If students who complete remedial education after the exit test requirement was implemented prove to be better prepared for college-level coursework than students prior to the exit test, some support will be given to the positive effect of the BSET. If enhanced levels of preparation are not apparent in the performance of remedial students following implementation of the BSET, then additional questions will be raised surrounding the validity of the examination, the cut score levels selected, and course curriculum or teaching strategies that impact student performance.

If a significant number of students are unable to pass the BSET and therefore experience the examination as a barrier they cannot overcome, particularly if a disproportionate number of them are minority students, evidence of negative consequences will be noted and could lead to further research. In sum, this study will foster a better understanding and appreciation of the impact of the BSET. 


\section{Definition of Terms}

$A C T$. A standardized achievement test that may be used by students for admission to college. Students who meet the minimum scores defined by the Florida Department of Education are exempt from further assessment and remedial coursework.

BSET. The Florida College Basic Skills Exit Test is the umbrella term for competency tests developed to certify student mastery of reading, writing and algebra skills upon completion of remedial coursework.

CLAST. The College Level Academic Skills Test is a standardized achievement test used to measure college-level computation and communication skills of students prior to awarding an Associate in Arts degree or acceptance into upper division coursework in the State University System.

CPT. The Florida College Entry Level Placement Test is part of the Accuplacer group of tests published by The College Board. It is the common placement test used by all Florida community colleges to assess entry level skills of students for placement into remedial courses.

FCAT. Florida Comprehensive Assessment Test measures elementary and secondary student achievement of skills represented in the Sunshine State Standards. The FCAT has a criterion referenced component and a norm-referenced component.

HSCT. The High School Competency Test was a high-stakes, standardized test used in the State of Florida to assess student mastery of basic competencies prior to award of a high school diploma. The HSCT was replaced by the Tenth Grade FCAT. $M-D C C$. Miami-Dade Community College is one of 28 colleges in the Florida Community College System. The College has 6 campuses and several centers throughout 
Miami-Dade County and enrolled over 71,000 credit, degree-seeking students in Academic Year 2000-01.

SAT. A standardized achievement test that may be used by students for admission to college. Students who meet the minimum scores defined by the Florida Department of Education are exempt from further assessment and remedial coursework.

\section{Summary of the Problem}

This study explores the impact and effectiveness of the latest Florida Statemandated high-stakes postsecondary test, the Basic Skills Exit Test, on the educational outcomes of remedial programs at M-DCC. The BSET is a high-stakes examination for students and may pose a barrier to their progress. It may also, as the state intended, serve to enhance the quality of remedial programs and ensure that students exiting the programs are better prepared for subsequent college-level coursework. The effectiveness of the BSET as a tool to enhance student achievement and certify student mastery of remedial objectives will be evaluated by examining the potential positive effects of the examination on student preparation and the potential negative consequences of the examination, especially for minority students. 


\section{CHAPTER II \\ REVIEW OF LITERATURE}

The use of minimum competency assessment is certainly not a new phenomenon. There is evidence of the use of tests to screen or select individuals for a wide variety of purposes dating back as far as 2000 B.C. (Cizek, 2001). The specification of minimum competency tests in public policies aimed at reforming education, raising standards, and enhancing accountability can be found throughout the world (Bishop, 1998; Leithwood \& Earl, 2000).

The use of such tests is popular among policy makers for a number of reasons, not the least of which is that on the surface minimum competency tests appear to accomplish many of the goals intended. There is evidence that curricular reforms, consistent standards, and enhanced student performance follow the implementation of minimum competency tests. There are also studies that question some of the apparent gains made by students on the tests and whether test score gains mean anything beyond the test in question. In other words, is student performance on related tasks or tests enhanced as well, or is the gain seen only on the specific test?

Since these tests are considered high-stakes for students, and often for educational institutions as well, the decisions made based on these tests have real consequences. There is evidence in the literature of negative consequences linked to decisions made on the basis of these high-stakes tests. This chapter explores the use of high-stakes, minimum competency tests for education reform and accountability, the evolution of public policy in Florida that led to the implementation of the Basic Skills Exit Test requirement, and the positive and negative consequences of high-stakes tests. 
High-Stakes Tests for Education Reform and Accountability

"Two presidents, the National Governors Association and numerous blue ribbon panels have called for the development of state content standards for core subjects and examinations that assess the achievement of these standards" (Bishop, 1998, p. 1). Arguably, high-stakes assessment has become the tool of choice for policy makers hoping to improve educational quality and accountability. It is clear that assessments with stakes attached generate action on the part of educational institutions, professionals, teachers, and/or students depending on the nature of the stakes. Policy makers have a history of using tests and related sanctions as tools to improve instructional achievement. Airasian and Madaus (1983) explain that policy makers can do little to improve instruction directly, so instead they make policy about testing, which is a relatively simple, inexpensive and well-developed technology. When students are held accountable by being denied diplomas or the ability to advance to the next level, changes occur in classroom instruction and students' study habits in order to pass the exam (Airasian \& Madaus, 1983, p. 108).

Scope and Extent of High-Stakes Assessment

Haney and Madaus (1986) claim that most significant educational reform efforts either mandate new tests or expand the use of existing ones. At the time the article was written, 37 states had state assessment programs of some type and eight states used highstakes promotional tests. More recently and more specifically related to postsecondary education, The National Center for Postsecondary Improvement (1998) evaluated the extent and scope of publicly mandated assessment. State assessment programs were classified according to policy type with the most common being assessments for quality 
assurance ( 36 states), followed by assessments for accountability (31 states). More than half of the states had assessment policies that served both purposes.

Ewell (2001) lists three principal types of statewide testing programs with distinctive purposes. Programs designed to certify student readiness or achievement, such as the BSET, make decisions about individual students based on demonstrated level of achievement. Secondly, programs designed to induce particular kinds of institutional behavior attempt to force institutions to improve their quality. Finally, programs designed to demonstrate accountability inform the public about educational institutions, with the secondary effect of inducing change in poor-performing institutions. On a national level, statewide testing programs serve a variety of purposes. The primary purpose of the BSET is to certify student achievement in order to ascertain readiness for subsequent coursework. This study explores how well the BSET serves this purpose by assessing differences in student success in subsequent courses before and after the introduction of the test.

Effects of Testing Programs on Educational Reform and Accountability

Statewide testing programs also have important symbolic value. Legislators and the public believe in the efficacy of testing programs to set and enforce educational standards. Testing programs often signal change, reassuring legislators and the public that something is being done to improve the quality of education. Madaus and Kellaghan (1983) use six principles to describe the effects of tests used in the policy sphere. Among these principles is the perceptual phenomenon of tests, which strengthens their symbolic value: “...if students, teachers, or administrators believe that the results of an 
examination are important, it matters very little whether this is really true or false - the effect is produced by what individuals perceive to be the case" (p. 9).

Another principle described by Madaus and Kellaghan (1983) is that teachers will teach to the test when important decisions are made based on results. As important decisions about students are made based on BSET results, faculty may respond by teaching to the test to enhance students" pass rates. The third principle is that "in every setting where a high-stakes test operates, a tradition of past exam questions develops, and this tradition eventually comes to define defacto the curriculum" (p. 9). Past BSET exam questions are frequently used in the remedial courses and may well be influencing the curriculum. Another principle used by Madaus and Kellaghan (1983) that may apply to the BSET is that "a high stakes test transfers control over the curriculum to the agency that sets or controls the exam" (p. 9). Even though community college representatives contributed to the development of BSET exam competencies, agreement and consistency between colleges was necessary, leaving little room for institutional flexibility in determining remedial course objectives.

\section{Summary of High-Stakes Tests for Education Reform and Accountability}

High-stakes tests have long been popular among policy makers wishing to influence the educational process. Such tests may be used to certify students' achievement (as in the BSET), hold schools accountable for educational outcomes, and shape the curriculum. One of the most important aspects of high-stakes testing programs seems to be their symbolic value: The public and legislators believe in the power of tests with sanctions to improve education. The use of such high-stakes testing programs comes 
with potential pitfalls, which will be discussed further in the section on consequences of high-stakes testing.

Public Policy and the Use of Tests in Florida

The State of Florida has a long history of attempting to stimulate educational reform through minimum competency testing. One of the landmark court cases in highstakes testing, Debra P. v. Turlington in 1984, was based in Florida and challenged the use of the High School Competency Test to award (and deny) high school diplomas. This case set precedents that are often referred to in testing literature, including opportunity to learn (OTL) standards.

\section{Public Policy and Educational Reform and Accountability in Florida}

Frustrated by its poor ranking among the states in educational quality and outcomes at both the K-12 and postsecondary levels, the Florida State Legislature has assumed an active role in shaping curriculum, assessment, and results. Through mandated placement testing, publication of test results, comparisons between high schools and between postsecondary institutions, as well as accountability standards linked to school or college president evaluations and/or funding, the Florida State Legislature's intent to force improvement is clear. The BSET requirement is yet another strategy to address an Achilles' heel in education: remediation at the college level.

The enactment of the Postsecondary Education Act (Florida House Bill 1545) in 1997, which included the BSET requirement, also mandated other educational accountability reforms and exemplified the Florida State Legislature's continuing desire to influence the efficiency and effectiveness of remedial education at the college level. The same legislation limited students to one state-funded attempt in a given remedial 
course, requiring students who needed to repeat the course to pay the full cost of instruction for the course. The State of Florida Department of Education was instructed through this legislation to conduct a study of remedial students to determine who is most likely to succeed.

Additionally, the Postsecondary Education Act addressed the growing problem of students graduating from high school with basic skill levels that were considered inadequate for college-level courses by creating a new classification of high school diploma - the college ready diploma. This special diploma is earned upon completion of specific courses and placement examinations that attest to the academic preparedness of the students and guarantees admission to the community college system without additional placement testing or remedial course requirements.

Furthermore, by 1997 every community college in the Florida Community College System was required to begin administering the single placement test approved by the State of Florida, the Florida Computerized Entry-Level Placement Test (commonly referred to as the CPT), published by The College Board. Colleges were also required to begin using the higher-level placement test scores for determining remedial needs that were chosen by the Student Assessment Section of the State of Florida Department of Education and initially mandated by the 1996 Florida State Legislature. The Florida State Legislature's interest in promoting consistency among colleges, improving the quality, and enhancing the progression and success of students in the remedial programs is evident in the Postsecondary Education Act.

Prior to the Postsecondary Education Act, the 1995 Florida State Legislature made a number of changes designed to enhance the accountability of remedial programs, 
including the requirement that students pass the CPT in order to exit from remedial coursework. This requirement met with strong objections by test administrators over the use of a placement test instead of a competency test to exit remedial courses and thus was never implemented. Other options were considered including a state developed and administered examination similar to the College Level Academic Skills Test (CLAST), which students must pass before earning an Associate in Arts degree or advancing to upper division level coursework.

However, the consensus was that "a state-developed and state-administered test required for exit from remediation would pose an additional barrier to those students whose skills improve by exposure to challenging and relevant courses" (Staff of the Committee on Higher Education, 1996, p. 10-11). Such a barrier would be contrary to the 'open door' policy of the community college system. Instead, colleges were afforded more flexibility in BSET development and administration in that the exam can be administered in the classroom to minimize test anxiety, colleges can prepare their own test forms as long as they adhere to test blueprints and use items from the pool provided, and colleges can set passing scores they believe are appropriate (T. Fisher, personal communication, November 12,1997$)$. At this time there is no common passing score, nor is there any public reporting requirement of BSET scores, which are two common elements in testing for educational accountability and improvement. Nevertheless, the BSET serves a gate-keeping function and can be considered high-stakes because students' future progress depends on passing the exam. The BSET also serves an accountability function (albeit without the 'teeth' at this time) in that it was intended to 
enhance the quality of remedial programs and ensure that remedial students are adequately prepared for college-level courses upon completion of remediation. Development of the Florida College Basic Skills Exit Tests

To implement this new testing requirement the Student Assessment Services Section of the Florida Department of Education contracted with the University of Florida to develop the test forms, test blueprints, item specifications and test items, based on competencies agreed upon by a panel of college representatives. The University of Florida formed three teams made up of subject matter experts from around the state to define the competencies for reading, writing, and mathematics. It was apparent as the teams met that community colleges had different competencies, objectives and expectations for remedial instruction. These differences were most apparent in mathematics where competencies taught in remedial courses in one college were taught in the first college-level course in another college. Initial competencies were defined and development of exit test blueprints continued in spite of these differences. After the initial competencies were defined, item-writing teams with membership from community college faculty wrote items for each of the three subject areas (J. Rich, personal communication, June 16,1997$)$. Because consensus on the competencies was not reached during the initial test development stage, revisions to test materials were made after the community colleges were able to achieve greater consistency across colleges in remedial course content (J. Hunter, personal communication, January 26, 1998). Additional items were developed and test blueprints were updated to meet the revised competencies in 1999. 
Original test materials were delivered to community colleges in December, 1997 and colleges were required to begin using the Basic Skills Exit Tests. During the implementation phase of the BSET, community colleges were responsible for setting their own passing scores to certify student attainment of basic skill levels requisite to success in college-level courses. The final, and current, version of BSET materials was delivered to the colleges in 1999. All three subject area tests are composed of multiple choice items; the writing BSET exam also includes a holistically scored essay, with prompts and scoring rubrics provided in the materials. Blueprints for the BSET examinations are included as Appendix A and a description of BSET materials is included as Appendix B.

\section{Implementation of the BSET Requirement at Miami-Dade Community College}

The Basic Skills Exit Tests were piloted at M-DCC prior to implementation to assist in setting passing scores. Students' BSET scores were compared with other criteria such as final grades assigned by faculty for the course and scores on departmental finals. Ranges and mean scores were reported for each of the subject areas by ethnicity and campus to anticipate the impact on M-DCC students (Bashford, 1998). Item analysis results were reviewed to identify items that appeared to be too easy, too difficult, or ineffective in discriminating between higher and lower scoring students. As a result of this pilot, several items were replaced and passing scores were adopted for the College by the academic deans. Additional analysis of BSET scores was conducted after the first administration of the revised BSET materials delivered in 1999 (Rodriguez, 2000).

Based on pilot results the BSET passing score was set at $60 \%$ for reading, writing, and mathematics, with the expectation that this score would be reviewed and increased in 
the future. At this passing score level, student pass rates varied from $55 \%$ for one of two exit level remedial algebra courses to $88 \%$ for the exit level remedial reading course. For the subgroup of students who had passed course requirements based on faculty determination, the BSET pass rates rose to $69 \%$ for the same algebra course and $94 \%$ for the reading course. The potential impact on students, particularly in the mathematics subject area, was clear -- $31 \%$ of students who would have successfully completed the algebra course would be required to repeat the course due to failing BSET scores (Bashford, 1998).

A college-wide task force was convened in 1997 to develop BSET administration procedures. It was determined that the BSET would be administered in the classroom during final exam week to students completing the highest level remedial course in a given subject. Students would need to pass both the final course in the sequence and the BSET in order to successfully exit the remedial course sequence. In the event the student successfully completed all course requirements but not the BSET, an opportunity to retest on the BSET would be provided. Students who still did not pass the BSET would be required to repeat the remedial course and retest on the BSET upon completion of the course. In rare cases, faculty could refer students who failed the BSET, but otherwise did exceptionally well in class work, to retake the CPT. If the student then scored above the state-mandated cut score he or she would be permitted to progress to college-level courses (J. Bashford, personal communication, April 22, 1998; N. Hendrix, personal communication, August 12, 1998). 
In summary, following an established tradition of mandating tests to ensure educational quality and accountability, the Florida Legislature introduced the BSET to target remedial programs at the college level. Contrary to other mandated testing, however, community colleges are currently able to set their own passing scores and are not required to report BSET results to the State. Discussions at the state level suggest that this may change as the BSET moves out of the implementation phase and finds a place in Florida's educational accountability standards.

\section{The Consequences of High-Stakes Testing}

A well-known tenet of testing is that "an educational decision that will have a major impact on a test taker should not be made solely or automatically on the basis of a single test score" (Heubert \& Hauser, 1999, p. 3). Tests are only snapshots of a student's ability at a given time, and may not accurately represent true ability. Tests, of necessity, must be comprised of a set of items that sample the domain, usually following some sort of test blueprint that specifies how (and how many) items should relate to each objective or competency in the subject area. Therefore, educators and test publishers generally agree that tests should supplement other information that is known about a student's knowledge in the subject area. High-stakes tests, however, appear to stand alone in judgment of a student's mastery or competency level (or the effectiveness of a teacher or educational institution) and have come under intense scrutiny as a result (Coleman, 2000; Heubert \& Hauser, 1999). 
There is a plethora of literature professing the negative consequences of highstakes tests (Black, 1998; Dunne, 2000; Heubert \& Hauser, 1999; Kohn, 2000; Lewis, 2000; Linn, 1998). Shepard (2000) discussed many of these possible consequences in the Presidential Address at the 2000 Annual Meeting of the American Educational Research Association, including inflation of test scores due to teaching to the test, distortion of the curriculum to focus on skills included in the test (often low-level skills as opposed to higher-order skills), as well as the 'deskilling and deprofessionalization' of teaching as teachers are forced to rely on memorization and drill and practice instead of fostering creativity and enthusiasm for learning in their students. One need not look hard or far to find other allegations of the negative effects of high-stakes testing on teaching and learning. Kohn (2000) describes as possible consequences: cheating (by students and teachers); animosity between teachers and lower-performing students who are viewed as liabilities when teachers and schools are rated on the basis of high-stakes test results; increased defensiveness and competitiveness on the part of teachers and schools; and reduction of curricular goals to test performance.

Lewis (2000) cautions policy-makers and evaluators to be attentive to potential negative consequences related to high-stakes tests when listing questions that should be addressed in test evaluations. Does use of the test have a disparate effect on minority student retention or success? Does use of the test encourage 'teaching to the test' and narrow the curriculum and instruction as a result? Does use of the test discourage students who are at risk of failing from even bothering to try? 
In a study of high school exit examinations, Linn (1998) identifies another negative consequence of high-stakes minimum competency examinations. "High school graduation tests also pose a problem because they do little to motivate high-achieving students. In the minds of many students, the minimum level of knowledge and skills required to pass the test becomes the maximum level of knowledge and skills they need to acquire in high school" (p. 4). Are we sending the wrong message to students with minimum competency tests? Do the tests de-motivate higher-performing students by suggesting that the minimum competency level is all that is needed instead of encouraging, recognizing, and rewarding higher levels of achievement? Further, are we setting students up to equate learning with extrinsic rewards or punishments, shifting the focus from internal motivation to external (Linn, 1998)?

Many of the negative consequences described in this section are most relevant when test results are publicized and schools or teachers are compared on the basis of the test results, neither of which currently characterizes the use of the BSET in Florida. However, many of the potential consequences are relevant, especially narrowing of the curriculum, teaching to the test to enhance student performance without accompanying increases in student learning, de-motivating higher-performing and discouraging lowerperforming students, and any disparate effects on minority students that would impede access to postsecondary education. The methodology employed in this study explores the impact of the BSET on minority students' progress.

Teaching to the test. What do we really know about these alleged negative consequences? It seems that research evidence to support or refute these allegations is scanty compared with literature professing the possibility of such consequences. In a 
study conducted on the oft-cited Texas Assessment of Academic Skills (TAAS) program in Texas, score gains on the TAAS were compared with score gains on the National Assessment of Educational Progress (NAEP) in reading and math (Klein, Hamilton, McCaffrey, \& Stecher, 2000). If students were learning more reading and math, then score gains should be similar on both examinations. And, conversely, if increased scores were the result of narrowing the curriculum, teaching to the test, or another response to the pressure to increase student scores, the NAEP gains would not likely correspond with TAAS gains. The researchers found that the gains were not comparable. Gains on the TAAS were much larger than gains on the NAEP. Also, researchers found that the gap between white and minority students appeared to widen when measured using NAEP results, even though the gap narrowed remarkably when measured using TAAS results. The researchers claim that their findings shed doubt on the validity of TAAS score gains and point out the need to validate state and high-stakes examinations using some external criterion, given the importance of decisions made on the basis of test results (Klein et al.).

Haertel (1999) expressed similar doubts about apparent score gains during the first few years of high-stakes testing programs, stating that gains on one test do not appear to generalize well to other tests with similar content and format. "If year-to-year score gains do not even generalize to similar tests, it is hard to imagine that such changes tell us much about proficiency across the rest of the school curriculum, let alone the use of academic knowledge in real-world contexts" (p. 8).

Teaching to the test may not be inherently undesirable as long as the test is well designed to measure higher-order skills, not just minimum skills, includes a variety of response formats, and is culture fair. In a study of state-level minimum competency 
testing programs, Marion and Sheinker (1999) did not find that the tests met that challenge. The authors reviewed minimum competency tests in use throughout the United States and concluded that while tests are getting better, they still rely primarily on multiple choice items and do not appear to measure knowledge and skills appropriate for education and work in the $21^{\text {st }}$ century. "If the curriculum is focused on teaching basic skills, students will likely improve in this area, but the importance of this finding is questionable" (p. 2).

Narrowing the curriculum. High-stakes minimum competency tests such as the BSET assume that students learn skills in the same order; that attainment of lower level skills is a prerequisite to learning higher-level skills. Without demonstrating such attainment on the exam, students cannot be considered 'ready' to progress to higher-level courses. Many researchers take issue with this assumption, however, arguing that students do not all learn in the same sequence of steps (Frederiksen, Mislevy, \& Bejar, 1993; Glaser \& Silver, 1994; Shepard, 1991). They contend that more recent findings in cognitive psychology challenge the notion that basic skills must precede complex thinking. While some basic skills may be essential, exposure to more complex problems or issues in context can spark enthusiasm in students that leads them to acquire the skills necessary to understand and solve such problems. High-stakes minimum competency tests are not designed to accommodate such a learning path (Marion \& Sheinker, 1999, p. 8-9).

"The use of minimum competency tests rests on an obsolete theory of learning. . Most learning theorists agree that sequential views of human learning where students are expected to progress along the same linear continuum until they reach subject-matter 
mastery do not hold anymore" (Marion \& Sheinker, 1999, p 21). In cognitive theories, learners must make sense of all new knowledge (even basic skills) by constructing or adapting mental schemas (Shepard, 1991, p. 8). All learning requires inference and judgment on the part of the learner, suggesting that thinking comes before, not after, the development of basic skills. Isolating basic skills instruction from higher-order knowledge would be counterproductive from this theoretical vantage point. A growing body of research suggests that learning is a complex process, which cannot be reduced to small steps or components (Black, 1998). According to Shepard, tests should also avoid oversimplification and the isolation of skills from thoughtful contexts (p. 9). She invites testing directors to re-evaluate their beliefs about learning and the appropriateness of the tests used to measure such learning. The BSET, with its multiple choice format and emphasis on minimum competency in basic skills appears to be based on the learning theory of behaviorism. If this is so, then using the BSET to decide if students are ready for subsequent courses may be inappropriate, as scores would not likely be reliable indicators of students' ability to succeed in the subsequent courses.

De-motivating students and discouraging achievement. In a study conducted on the Florida High School Competency Test, Griffin and Heindorn (1996) found that failing the test encouraged students to drop out of school. Those students most influenced by failing the test appeared to be the low-average achieving students. It seems likely that college students who are struggling academically would react similarly when faced with failing a high-stakes exit exam such as the BSET. Dropping out of college is probably much easier than dropping out of high school as it simply means the student stops registering and paying for additional courses. If the same students would continue to have 
difficulty in future courses and eventually drop out, then this may not be an undesirable outcome. However, if students who would otherwise have been successful ultimately are dropping out due to failing the exit exam, then this is clearly not the best outcome.

Adverse impact on minorities. In a study on the predictive validity of another Florida state-mandated high-stakes exam, the College Level Academic Skills Test (CLAST), Garcia (1995) found that approximately two thirds of the Miami-Dade Community College students who succeeded in subsequent coursework would have been denied the opportunity to progress to that level due to failing CLAST scores. Minorities appeared to be most likely to be held back due to the CLAST, as the likelihood of an incorrect decision being made on the basis of the test was higher for Hispanic and Black non-Hispanic students. He concluded that the predictive validity of the exam was unacceptably low and inappropriate decisions were being made about students based on the exam.

Natriello and Pallas (1998) reviewed the impact of exit examinations in Texas, New York and Minnesota by comparing performance patterns of students in different racial/ethnic backgrounds. In all cases they found that minority students performed less well than majority students. Limited English proficient students also performed less well than native English speakers.

In GI Forum v. Texas Education Agency, the Texas graduation test was challenged based on alleged discrimination against Hispanic and African-American students (Phillips, 2000; Schafer, 2000; Ward, 2000). The test was alleged to have an adverse impact on minorities, as the performance of minority students was significantly lower than that of majority students. In one method of calculation, the drop out and grade 
retention rates for minority students increased following introduction of this graduation requirement. The Court ruled in favor of the Texas Education Agency (TEA) stating that although the test did adversely affect significant numbers of minority students, the TEA had established that the test was necessary to identify and address educational problems experienced by minority students. The court also found that a test administered only in English was valid for students whose native language is not English. This finding seems to confirm that adverse impact will be tolerated if the need for, and benefits attained through the use of, a high-stakes test can be established. In this instance, the graduation test, with its attendant high-stakes for students and schools, was used to identify lowperforming schools and target them for improvement efforts. The Basic Skills Exit Test does not currently serve that purpose although the stakes are still high for students who are denied the opportunity to progress because they failed to attain passing scores.

\section{Potential Positive Consequences}

As with the potential negative consequences of high-stakes testing, it is much easier to find articles alleging the positive effects of high-stakes testing than it is to find research findings that support these claims. Among the potential positive consequences cited in a recent article are the 'trickle-down' effect of well-designed assessments on teacher-developed classroom tests, the improvement of programs to enhance student success based on test results, more thorough understanding of their disciplines by educators, and increased student learning (Cizek, 2001).

In a seemingly thorough evaluation of the impact of curriculum-based external exit exam systems (CBEEES) on student achievement, Bishop (1998) concluded that the examinations do, in fact, encourage greater learning and result in higher achievement. $\mathrm{He}$ 
compared nations, states and provinces that had CBEEE systems with those that did not using student scores on the National Assessment of Educational Progress (NAEP), the Third International Mathematics and Science Study (TIMSS), and the International Assessment of Educational Progress (IAEP). Student scores were higher in places where CBEEES were in place.

One important characteristic of the CBEEES studied by Bishop in 1998, however, is lacking in the BSET at this time: recognition of multiple levels of achievement in the subject area, not just pass or fail outcomes. Minimum competency examinations with pass/fail outcomes do not motivate students to achieve at higher levels. "When a test generates only a pass/fail signal, many students pass without exertion and are not stimulated to greater effort by the reward for passing. Some of the least well-prepared students will judge the effort required to achieve the standard to be too great and the benefits too small to warrant the effort" (Bishop, 1998, p. 2). This important point is corroborated by Griffin and Heindorn (1996) in their study of the Florida High School Competency Test, which was discussed earlier.

In addition to increasing student learning, Bishop (1998) also found that CBEEES had other effects, which are not likely dependent on multiple achievement level signals. Schools with exit examinations were found to schedule more math and science instruction, assign more homework, and have better labs and more qualified teachers. Teachers reportedly gave tests and quizzes more frequently in schools with exit exam systems.

Bishop (1998) also claims that teachers feel relieved from the pressure to pass marginal students when the external exit exam serves as the final grade determinant. 
Another benefit, reported for teachers, was the opportunity to collaborate with other teachers in the development, review, and/or scoring of the examinations leading to improvements in instructional practice (p. 5). Prus and Johnson (1994) reported that when faculty participate in the development of the examinations, clarification of what is important in the process and content of student learning will likely result (p. 72). These final benefits may well result from the BSET since faculty can rely on the exit exam to justify failing low-performing students who, nevertheless, insist that their work is adequate. Faculties also meet to review and discuss the use of the BSET, providing opportunities to share instructional strategies that are promising or successful. Summary of Potential Positive and Negative Consequences of High-Stakes Tests In summary, there seems to be relatively little evidence supporting the many claims of potential positive and negative consequences associated with high-stakes testing. While scores do tend to increase in the first few years after a high-stakes test is introduced, there is some evidence that the gains do not generalize to other tests or contexts. Advocates of cognitive theories of learning question the value and impact of isolating skills in instruction and testing, and call for revisions to testing practices. Curriculum based external exit examinations do seem to increase student learning although having multiple levels of achievement recognized seems to be critical to avoid de-motivating better students and discouraging poorer students. Other reported benefits to teachers and schools may serve to improve the quality of instructional programs.

\section{Summary}

This chapter presented relevant findings from the literature related to high-stakes testing for educational reform and accountability, public policy and the BSET in the State 
of Florida, and the consequences of high-stakes tests. It is clear that high-stakes tests are popular among policy makers attempting to improve educational outcomes. High-stakes tests have had a long history and continue to be used widely. There is evidence that such reliance on high-stakes tests will continue on the state and national level.

The State of Florida has frequently turned to high-stakes tests in an effort to introduce greater accountability into the educational system and enhance student achievement. Tests have been mandated for the K-12 system for student grade level assessment and high school graduation decisions, as well as for grading and comparing schools. At the college level, high-stakes tests have been mandated to certify student mastery of college-level academic skills. Most recently, the BSET was introduced to ensure that students master specific remedial program objectives and competencies.

In spite of the popularity of high-stakes tests, and speculation about their impact, the literature is relatively sparse in studies that report evidence of positive or negative consequences. There is some evidence that high-stakes curriculum-based exit examinations promote higher student achievement. There are also studies that report that high-stakes test score increases do not generalize well to other tests or educational settings. Additionally, high-stakes tests have been shown to have a negative, and disparate, impact on minorities and non-native English speakers. 


\section{CHAPTER III}

\section{METHODS}

This chapter presents the research methods used in this study. The chapter begins with an overview, after which an explanation of the methods employed is given. A detailed description of the participant selection process is included with separate sections for the cohorts defined for Hypotheses 1 and 2, Hypotheses 3 and 4, and Hypotheses 5 and 6. Diagrams are included following the narrative description for each of the cohorts to illustrate the process. A discussion of the instruments utilized in the study, the research design, and data processing and analysis techniques are also included. Methodological assumptions and limitations of the method complete the chapter.

\section{Overview}

This study consisted of an ex post facto research design (causal-comparative) to determine the impact of the Basic Skills Exit Test (BSET) on student success and readiness for subsequent college-level coursework at Miami-Dade Community College (M-DCC). Data for the study were compiled from secondary data files, which store demographic and course information for students at M-DCC. In addition, BSET score information was obtained from the campus academic departments where the tests were originally processed.

Participants included in this study were limited to students enrolled as degreeseeking (Associate in Arts or Associate in Science) at M-DCC. Miami-Dade Community College is a large, multi-campus community college located in South Florida, with approximately 71,000 credit students enrolled in Academic Year 2000-01. A high proportion of M-DCC students are minorities; $21.6 \%$ Black non-Hispanic, $64.8 \%$ 
Hispanic, $1.9 \%$ Asian, Indian, or other minority, and the remaining $11.7 \%$ White nonHispanic in the Fall Term 2001 enrollment (Institutional Research, 2002).

The statistical treatments used in this study include analysis of variance to compare the performance of remedial and college-ready students before and after the BSET. Chi-square analysis was used to explore changes in the proportion of students completing and passing remedial courses. Finally, correlation analysis was used to explore the utility of the BSET in predicting subsequent college-level course performance. Race/ethnicity was included in this analysis as research indicated that highstakes examinations such as the BSET could disproportionately impact minority students.

Research questions and Hypotheses are defined in Chapter 1. To enhance the clarity of presentation of the statistical analysis results, the following null Hypotheses were tested at an alpha level of .05:

$\mathrm{H}_{\mathrm{O}}$ 1: There will be no significant difference in grade point averages in collegelevel courses between students who completed remedial instruction after the introduction of the BSET requirement and students who completed prior to the requirement for each of the subject areas of reading, English, and mathematics.

$\mathrm{H}_{\mathrm{O}}$ 2: There will be no significant difference in grade point average in collegelevel courses for students who completed remedial instruction after the introduction of the BSET requirement when compared with college-ready students for each of the subject areas of reading, English, and mathematics. 
$\mathrm{H}_{\mathrm{o}}$ 3: There will be no significant relationship between remedial course completion and success rate and the BSET requirement.

$\mathrm{H}_{\mathrm{O}} 4$ : There will no significant relationship between remedial course completion and success rate and the BSET requirement for minority students.

$\mathrm{H}_{\mathrm{O}}$ 5: There will be no significant relationship between BSET score and collegelevel course GPA.

$\mathrm{H}_{\mathrm{O}}$ 6: There will be no significant relationship between BSET score and collegelevel course GPA for minority students.

Research Methods

This study is based on a causal comparative design with student data obtained from secondary data files at Miami-Dade Community College. These database files contain initial placement test scores, student demographic information including race/ethnicity, and a record for each course the student took that term with grades earned. Information was extracted from these files to create nine separate cohort files for this analysis, which included the dependent variable of grade point average in college-level course(s), and independent variables of group membership and race/ethnicity.

The BSET scores were obtained in electronic file format from the academic departments on four of the five M-DCC campuses that offer remedial courses. Data for one of the five campuses was no longer available in the academic department, or elsewhere, and therefore was excluded from the study. The electronic files grouped data by subject area and contained raw scores and percent correct scores for each student who took the BSET. Student identifiers were either missing or incorrect for a small percentage of the students, and therefore it was not possible to match all students enrolled in 
remedial courses with a BSET score. These individuals were also excluded from the study as appropriate. It was assumed that students for whom BSET scores were not matched were similar to students with matching BSET scores for the purpose of evaluating the relationship between BSET score and subsequent college-level course performance in this study. Previous institutional research using similar data sets had suggested no systematic differences between those few students eliminated due to administrative errors and students in the included sample.

Group membership was not based on random assignment of subjects. Specific selection criteria were employed to assign group membership; e.g. course enrollment, calendar year/term of enrollment, and initial level of academic preparation. New students enrolling in Miami-Dade Community College reading, English, or mathematics classes are required to take the Computerized Placement Test (CPT) for placement into remedial or college-level courses. The CPT cut scores used to exempt students from placement into remediation are set by the Florida Department of Education. Cut scores used to place students into the various levels within the remedial programs are set by the institution.

At M-DCC, the CPT score ranges used to place students into remediation remained the same for reading and English during the time period covered by this study. The CPT score range used to place students into remedial mathematics courses was expanded to include Algebra scores of $61-71$, since the cut score used to place students into MAT1033 was raised from 61 to 72 for new students enrolling Fall Term 1998-99. To compensate for this in statistical analyses that compared student performance before and after the BSET, students in the 1999-00 cohorts whose CPT scores were within the range of 61-71 were removed. 


\section{Participants}

The selection of subjects for this study involved the application of specific selection criteria to term-based student database files. These files contain demographic information for every student enrolled in credit courses at M-DCC including race/ethnicity, CPT scores used for course placement, and a record for each course taken with grades earned. As this study explored the effectiveness of the BSET in enhancing subsequent course performance, the relationship between BSET score and subsequent course performance, and the impact of the BSET on remedial course completion and success rates for each of three subject areas, nine separate but overlapping study populations were generated.

Study Populations for Subsequent Course Performance Analysis

The selection process for study populations for Hypotheses 1 and 2 is illustrated in Figure 1. Students were included in these study populations if they were enrolled in specific college-level courses during the designated Spring Terms, and had either completed the highest level remedial course in that subject area the previous Fall Term, or been placed directly into the college-level course by CPT scores. Student database files were searched separately for Fall and Spring Terms 1997-1998 for the pre-BSET population, and Fall and Spring Terms 1999-2000 for the post-BSET population. The three files created for this purpose included student identifier, race/ethnicity code, CPT score, course(s) enrolled Spring Term, letter grades earned, and grade point average for the specified course(s). Race/ethnic codes were collapsed into four categories according to M-DCC reporting conventions: Asian/Other, Black non-Hispanic, Hispanic, and White non-Hispanic. A separate data file was created for reading, English, and mathematics. 


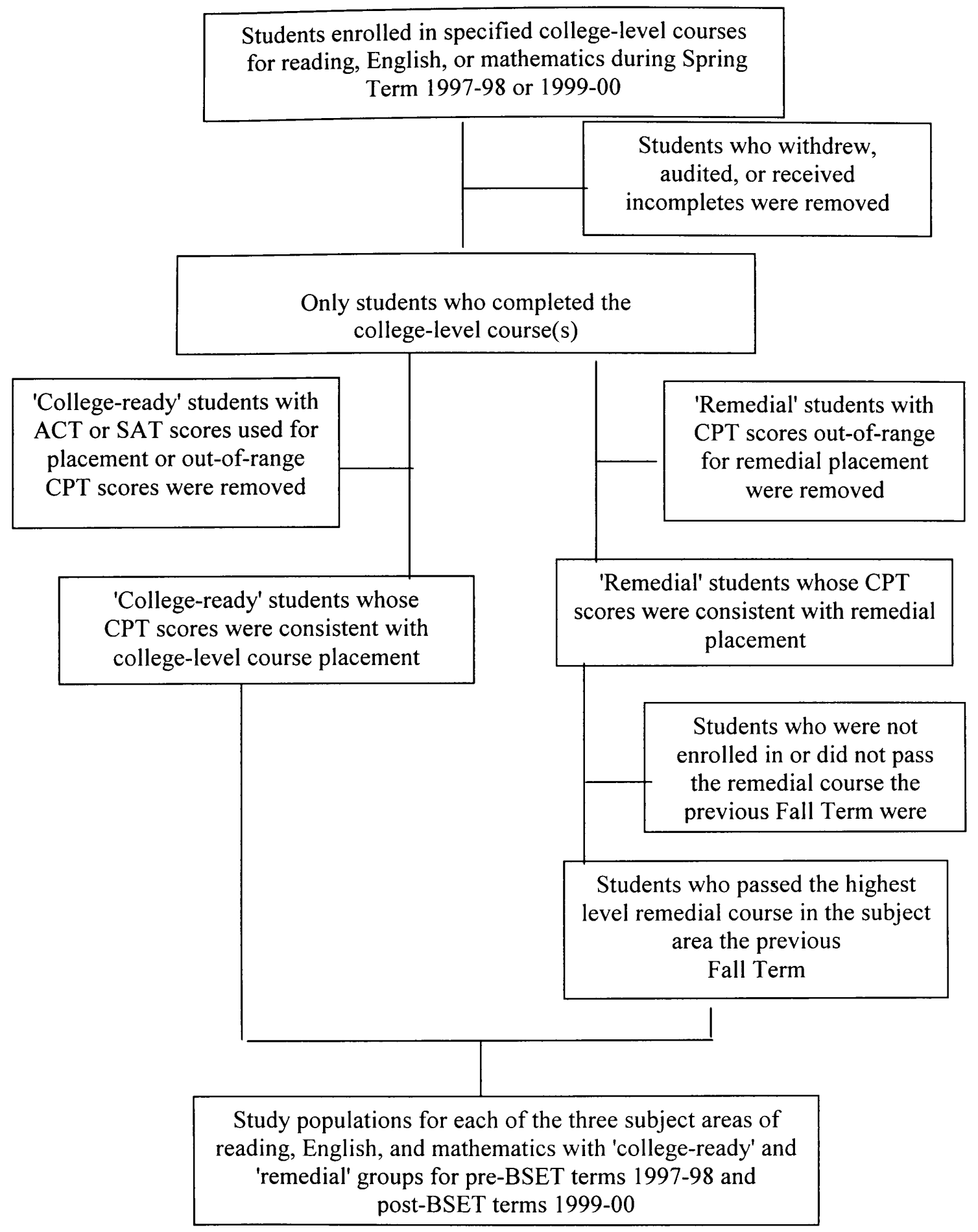

Figure 1. Selection process to derive study populations for subsequent course performance. 
Subject area classification. Students were included in the English study population if they completed ENC1101, College Composition, during one of the Spring Terms selected for the study. Students were included in the mathematics study population if they completed MAT1033, Intermediate College Algebra, during one of the two Spring Terms. Finally, students were included in the reading study population if they completed DEP2000, Human Growth and Development; HUM1020, Humanities; ISS1120, The Social Environment; and/or ISS1161, The Individual and Society, during one of the Spring Terms selected for the study. M-DCC does not require students to take a collegelevel reading course, so these courses were chosen because they are part of the general education curriculum, include a strong reading component, and had relatively high enrollment of remedial course completers in both of the Spring Terms selected for the study.

Students who were auditing the course(s), withdrew from the course(s), or received a grade of incomplete in the course(s) were excluded from the study. This analysis explored the impact of the BSET on the academic readiness of students for subsequent college-level courses. Any number of factors, related and unrelated to academic preparation, may influence a student's decision to withdraw from a course. The ultimate grade point average earned in courses that were completed was most relevant to this analysis. Students may appear on more than one file if they were placed directly into, and enrolled in, more than one of the designated courses during Spring Term 1997-1998 or Spring Term 1999-2000.

Remedial classification. Students were included and classified as "remedial" if they were enrolled in the highest remedial course in reading, English, or mathematics 
during Fall Term and the first college-level course(s) in the same subject area during Spring Term of the same academic year. This selection process eliminated students who did not enroll in the college-level courses specified for the subject area immediately following completion of the remedial course. This was done to minimize the effect of other intervening course enrollments or attrition of subject knowledge that may have occurred if the student delayed enrollment in the next course.

An additional check of CPT scores was made to ensure that students designated as "remedial" had CPT scores in the appropriate range for placement into remediation. Students with scores out-of-range for their actual course enrollment were deleted from the files. Special exceptions to placement rules were most likely made by advisors for these students due to other circumstances for which this study could not control.

College-ready classification. Students were included as "college-ready" if they were placed directly into college-level courses by CPT scores in reading, English, and/or algebra and enrolled in the course(s) during the Spring Term. All remedial course placements at Florida community colleges are made using scores earned on the CPT. Students can use ACT or SAT scores to be exempt from placement into remedial coursework if their scores meet or exceed state cut scores. For this study, students who entered college using ACT or SAT scores were not included. Other differences may exist between such students and those who took the CPT as part of the admission process, and the influence of such differences on course performance could not be controlled in this study. For example, students who took and exceeded the ACT or SAT cut score prior to admission may have been more motivated, or may have had stronger college aspirations 
than students who were tested on the CPT when applying for admission, and therefore be more likely to apply themselves and succeed in their coursework.

An additional check of CPT scores was made to ensure that all students designated as "college-ready" had CPT scores in the appropriate range. Students with scores out-of-range for their actual course enrollment were excluded from the study. Special exceptions to placement rules were most likely made by advisors for these students due to other circumstances for which this study could not control. Study Populations for Analysis of Impact on Remedial Course Completion and Success

Figure 2 illustrates the different selection criteria, which were used to explore the impact of the exit test on remedial student course completion and success for each of the three subject areas (Hypotheses 3 and 4). Students were selected from the term-based database files if they were enrolled in the highest remedial course in reading, English, and/or mathematics during Fall Term 1997-1998 (prior to the BSET requirement) or Fall Term 1999-2000 (after the BSET requirement). The three files created for this purpose included student identifier, grade earned in the remedial course for that term, race/ethnicity, and CPT score. A separate data file was created for each of the subject areas of reading, English, and mathematics.

Remedial course grades at M-DCC are as follows: S for successfully passed; PR for making progress but not passed; $\mathrm{U}$ for unsatisfactory progress; W for withdrawal; I for incomplete; and X for audit. For the purposes of this study, the few students with I or X grades were eliminated.

Students whose CPT scores were not in the appropriate range for placement into remedial courses were eliminated. Special exceptions were likely made for these students 
due to other circumstances for which this study could not control. Since students may have been enrolled in the highest level remedial course in more than one of the three possible subjects, they may appear in more than one study population.

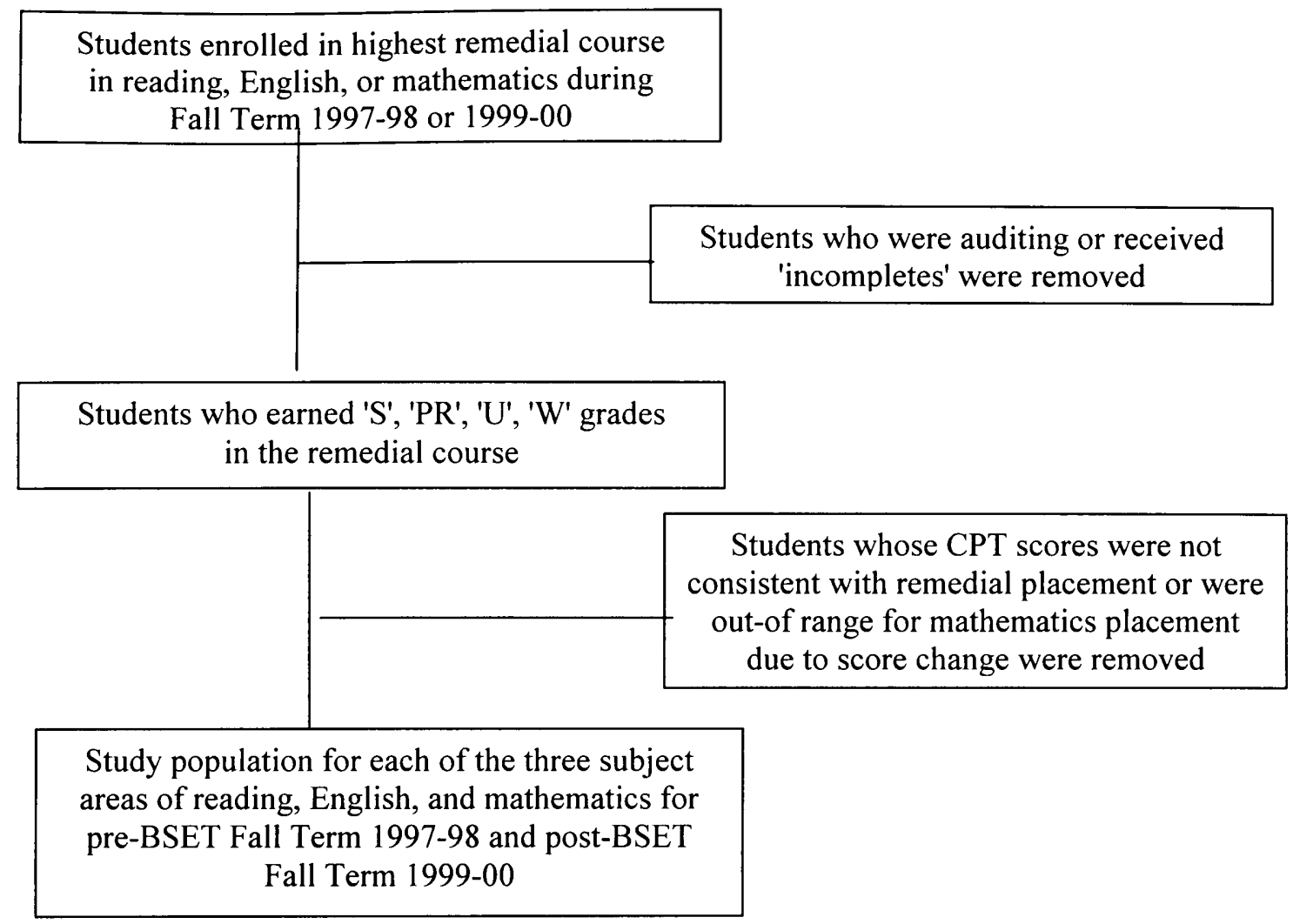

Figure 2. Selection process to derive study populations for analysis of impact on remedial course completion and success.

Study Populations for Analysis of Correlation between BSET and Subsequent Course

\section{Performance}

Figure 3 illustrates the selection process used to form the study populations for Hypotheses 5 and 6 . The study populations for the correlation analysis were a subset of the subsequent course performance analysis populations. To be included in the correlation analysis students must have been selected for inclusion in the aforementioned 
study populations to evaluate subsequent course performance. For the correlation analysis, only students enrolled during the Fall Term 1999-2000 were included, since they were subject to the BSET requirement. In addition, students were included only if BSET scores were available for them. Three data files were created for this purpose; one for each of the subject areas of reading, English, and mathematics.

All students enrolled in the highest remedial course in reading, English, or mathematics during Fall Term 1999-00

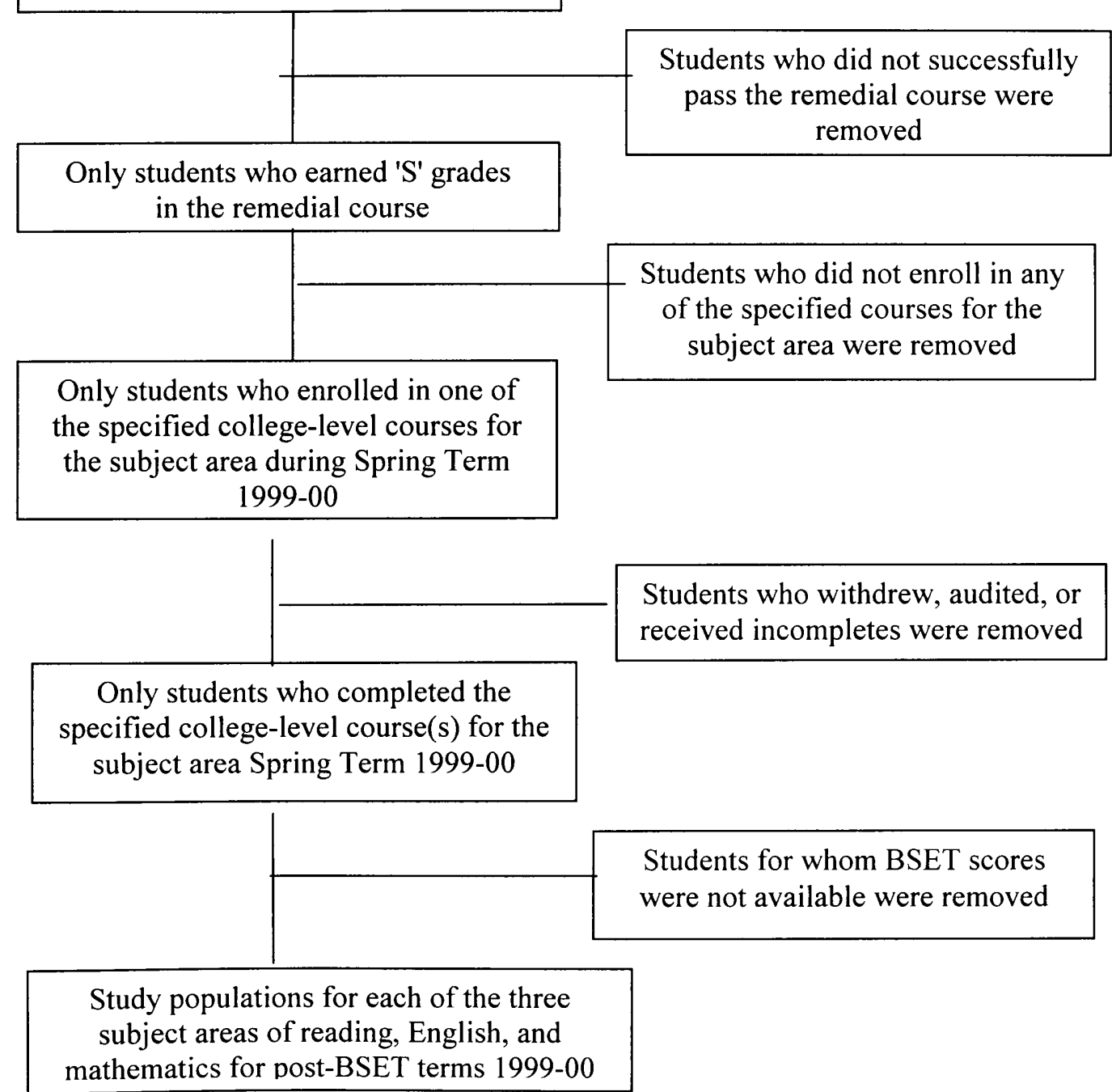

Figure 3. Selection process to derive study populations for analysis of correlation between BSET and subsequent course performance. 


\section{Instruments}

The Basic Skills Exit Test (BSET) was the primary instrument included in this study. In addition, the Computerized Placement Test (CPT) determined initial placement of students into remedial or college-ready groups for each of the three subject areas.

\section{Description of the BSET}

The BSET consists of three separate tests: a multiple choice reading examination; a multiple choice mathematics examination; and a two-part English examination consisting of a multiple choice component and a holistically scored essay. Reliability and validity have not been reported by the State of Florida for these examinations. The Student Assessment Services Section of the Florida Department of Education contracted with the Office of Instructional Resources (OIR) at the University of Florida to develop the examinations. OIR convened committees with representation from Florida Community Colleges to develop and validate the competencies to be included on the examinations; to develop and validate the blueprints used to match items with competencies and ensure appropriate coverage of all of the competencies; and to write and validate items for each competency.

According to the Student Assessment Section, validation of the competencies and blueprints consisted of input from subject matter experts on the committee and through a survey of community colleges. The individual items were piloted on groups of students, with the item writing committee reviewing the results to determine if items were functioning as intended prior to inclusion in the item bank. No reliability studies were prepared on the test forms prior to delivering to the community colleges, as these forms could be modified by the colleges if desired, as long as blueprints were followed and 
items were taken from the state-developed item bank. The State of Florida does not administer these examinations and data on student performance on the examinations is not currently collected by the State. (K. Fearon, personal communication, August 15, 2002; T. Fisher, personal communication, September 6, 2001).

\section{Implementation of the BSET}

At Miami-Dade Community College, the BSET is administered and scored by faculty in the respective academic areas. College-wide analyses of BSET scores were conducted prior to implementation and again in 1999 after the examinations underwent significant revisions (Bashford, 1998; Rodriguez, 2000). In the original analysis (Bashford, 1998), student scores on the BSET were compared with grades assigned by faculty based on student performance in class and on classroom examinations. Cut scores were chosen to maximize the concordance between faculty grades and BSET score.

For the reading subject area, $94 \%$ of students to whom faculty gave passing ' $\mathrm{S}$ ' grades also passed the BSET. However, $71 \%$ percent of the students who were assigned failing ' $U$ ' grades by faculty also passed the BSET. For the English subject area, $89 \%$ of students who earned ' $\mathrm{S}$ ' grades in the class also passed the BSET at the $60 \%$ cut score level; and $73 \%$ of the students who earned ' $U$ ' grades also passed. And for the mathematics subject area, $69 \%$ to $82 \%$ of the students who earned ' $\mathrm{S}$ ' grades also passed the BSET depending on the specific remedial mathematics course; and $9 \%$ to $21 \%$ of the students who had earned ' $U$ ' grades passed the BSET. The $60 \%$ cut score appeared to more closely match faculty assessment of student performance in mathematics than in the reading or English subject areas. (Bashford, 1998). Item analysis was also conducted for each of the test forms in this BSET review. Faculty reviewed items that appeared to be 
too difficult (less than $40 \%$ of students answering correctly) or too easy (close to $100 \%$ of students answering correctly). Alternate items from the item bank that assessed the same competency were substituted for most of these questionable items.

\section{Reliability of the BSET}

The reliability of the BSET was estimated for a sample of students who took the examinations during academic year 2001-02. In this analysis, internal consistency reliability was estimated using Kuder-Richardson 20 formula for each of the subject area examinations. For the reading subject area, 232 students were included in the sample, which yielded a reliability estimate of $r=.41$. For the English subject area, 234 students were included in the sample, which yielded a reliability estimate of $r=.51$. A sample size of 1,094 students was used for the mathematics analysis, which yielded a reliability estimate of $r=.79$. Nunnally (1978) suggests .70 as the minimum acceptable level of reliability, but also recommends .90 or higher when significant decisions are made based on test results. While the mathematics BSET is acceptable according to these guidelines, it is clearly not within the recommended range of .90 or higher. The reading and English BSET examinations failed to reach the minimum acceptable level of reliability. These results suggest that findings obtained in this study are likely to be confounded by the lack of reliability of these examinations. These results also suggest that these examinations should be reviewed thoroughly and revised as needed to improve their reliability since important decisions are being made based on test results.

In order to pass the remedial course, students are required to successfully complete assigned coursework and earn a passing score on the BSET. Students take the BSET at the end of the semester if their classroom performance is deemed satisfactory by 
faculty. Therefore, BSET scores are not available for students who were performing poorly in class at the end of the semester. Given this restriction of BSET score range, the reliability estimates obtained may be low estimates. Internal consistency estimates report on the homogeneity of items, or the degree to which items measure the same competency. Tests that include a variety of item types, or a heterogeneous set of competencies to represent the content area, are likely to have lower estimates of internal consistency. Additional indicators such as test-retest reliability estimates to reflect stability of test scores, or indices of decision consistency to assess accuracy of pass/fail decisions would be informative. (Nitko, 1983, p. 396-405.)

Summary of the BSET in Relation to This Study

This study does not attempt to report student performance on the BSET itself, rather the impact of the BSET on academic outcomes is explored. The Fall Term 19992000 administration of the BSET was chosen for inclusion in the study since it is the first term that the revised versions were used. These same versions are in use currently, although new forms have been derived from the same item bank following the same test blueprints and specifications.

The correlation between BSET score and performance in subsequent college-level courses is explored and reported to determine if the BSET has predictive validity for this purpose. In addition, the impact of the BSET requirement on students' completion and success in remedial coursework and differences in readiness for college-level work are explored to evaluate the impact of the BSET on academic outcomes. 


\section{Description of the CPT}

The Computerized Placement Tests are computer administered adaptive tests published by The College Board as part of the Accuplacer battery of placement tests. The tests are intended to assist in course placement decisions. Given that they are adaptive tests, the sequence of test questions varies from student to student. Five tests of the CPT battery are utilized at M-DCC to place students into reading, English and mathematics courses that are appropriately matched to their ability levels.

The Reading Comprehension test consists of approximately 20 multiple choice questions of two types. In the first type, students read a passage and answer questions about the content of the passage. In the second type, students are presented with two sentences and questioned about the relationship between the two sentences (The College Board, 1993). Scores on this test are used to place students into one of three remedial reading courses, or exempt them from the reading course requirement.

The Sentence Skills test also consists of approximately 20 multiple choice questions of two types. Sentence correction questions require students to choose the most appropriate word or phrase to replace an underlined part of the sentence. Construction shift type questions ask students to rewrite sentences according to criteria shown, without changing the meaning of the sentence (The College Board, 1993). Scores on this test are used to place students into one of three remedial English courses, or directly into the first college-level English course.

The Elementary Algebra test consists of approximately 12 multiple choice questions covering three areas: a) Operations with integers and rationals; b) Operations with algebraic expressions; and c) Solution of equations, inequalities and word problems 
(The College Board, 1993). Elementary algebra scores are used to place students into the Introductory Algebra course or to refer students for further testing in arithmetic or higherlevel mathematics skills.

Students who score below an established cut score on the Elementary Algebra test also take the Arithmetic test of the CPT, which consists of approximately 17 multiple choice items. Three categories of questions are included in this subtest: a) Operations with whole numbers and fractions; b) Operations with decimals and percents; and c) Applications and problem solving (The College Board, 1993). Scores on this test are used to place students into one of three remedial mathematics courses.

The College-Level Mathematics test is given to students who score above an established cut score on the Elementary Algebra test. It consists of approximately 20 questions covering algebraic operations, solution of equations and inequalities, coordinate geometry, algebraic applications, functions, and trigonometry (The College Board, 1993). Scores on this test are used to place students into College Algebra or other higher-level mathematics courses. Due to their placement into mathematics courses above the Introductory Algebra (MAT 1033) level, these students were not included in the study populations for this analysis.

Reliability and Validity of the CPT

The College Board reports reliability coefficients ranging from .86 for the College-Level Mathematics test to .92 for the Arithmetic and the Elementary Algebra tests. A large-scale study of the predictive validity of the CPT was conducted by The College Board in 1990-1992 using data provided by 50 colleges and universities. Correlations were reported for each of the tests reflecting the relationship between CPT 
score and course grades. Because students who were included in the validity study were placed into courses as a result of CPT scores, the resulting correlations are likely to be conservative estimates of validity due to restricted score ranges. Median correlations within institutions ranged from .18 for CPT Reading scores and remedial reading course grades to .53 for College-Level Mathematics CPT scores and calculus course grades (The College Board, 1993, p. 58-64).

Summary of the CPT in Relation to This Study

The CPT was used to place students into remedial reading, English, and mathematics courses in accordance with M-DCC placement policy. The use of the CPT for the purpose of determining need for remediation is mandated by the State of Florida in Florida Statute 240.117, Rule 6A-10.0315, FAC. The College Board has provided reliability and validity information that supports the use of the CPT for placement decisions. All of the students included in this study were placed, and therefore grouped into remedial or college ready categories, based on CPT scores.

Research Design

This study was designed to compare the performance of students who needed and successfully completed remedial instruction before enrolling in the first college-level course in the subject area before and after the BSET was introduced. The performance of these students was also compared with students who did not need remediation and were enrolled directly in the college-level course in the subject area instead. This second comparison was implemented to control for any differences in grading or instructional practices during the time period covered by the study that may have affected student success. Thus, a two-way ex post facto design was selected to test the impact of the 
BSET on subsequent college-level course performance for each of the three subject areas assessed by the BSET: reading, English, and mathematics.

\section{Analysis of Student Performance in Subsequent Courses}

The dependent variable in the analysis of variance, conducted as part of this study, was the grade point average earned in the first college-level course(s) in the subject area. Group membership and race/ethnicity were included as the independent variables. Race/ethnicity was collapsed into four major groups according to M-DCC reporting conventions: Asian/Other, Black non-Hispanic, Hispanic, and White nonHispanic. Initial level of academic preparation was reflected in students' group membership and verified by Computerized Placement Test (CPT) scores. Students were classified as either "remedial" or "college-ready" based on CPT taken upon initial enrollment. Cell sizes were not equal, so Type III Sums of Squares method was used for this unbalanced model.

As this study explored the impact of the BSET on remedial student performance in college-level courses and compared their performance with that of college-ready students, it was assumed that earned grade(s) in the relevant course(s) was most appropriate for this purpose, since other possible measures may have confounded the outcomes. For example, most courses did not have a common final examination, so using some other end-of-course metric instead of the earned grade may have created more variation. No attempt was made to adjust GPA for initial level of academic preparation, as these differences were part of the study design. To ensure comparability of the mathematics groups according to M-DCC placement rules, students whose CPT scores 
were in the range affected by the placement score change were eliminated from the cohorts.

Analysis of Impact on Remedial Course Completion and Success

Chi-square analysis was used to compare grade distributions of students taking the remedial courses before and after the BSET was introduced. Separate chi-square analyses were conducted for each subject area and race/ethnic group within the subject area. Race/ethnicity is included as the literature suggested that high-stakes examinations, such as the BSET, could have a disproportionate impact on the completion and success rates of minority students. CPT score ranges used for placement into remedial courses remained stable during the time period covered in this study in reading and English. For the mathematics subject area, students with CPT scores in the range of 61-71 were eliminated from the cohort to control for the influence of the placement score change. All students were enrolled in the same level remedial course either by CPT score or satisfactory progression from the prerequisite remedial course. Therefore, it was assumed that the remedial study populations before and after the BSET had similar academic skill levels upon enrollment in the highest remedial course in the subject area.

Analysis of Correlation Between BSET Score and Subsequent Course Performance

Finally, correlation analysis was performed to explore the relationship between BSET score and subsequent college-level course grade point average. Separate correlation analyses were performed for each subject area and race/ethnic group within the subject area. If the BSET has predictive validity within the subject area, significant positive correlations might be expected. For these analyses, the BSET scores of students who completed the highest remedial course in a subject area during Fall Term 1999-00 
were correlated with the grade point average earned in related college-level course(s) taken the following Spring Term 1999-00.

\section{Data Processing and Analysis}

The data used in this study were retrieved from secondary data files at MiamiDade Community College. All of the data elements used in this study were available on these data files, with the exception of the BSET scores. The BSET scores were obtained in electronic form from the remedial reading, English, and mathematics academic departments on the M-DCC campuses. The BSET score files were converted to SAS datasets and uploaded to the mainframe. The statistical analysis of the data was performed using the Statistical Analysis System (SAS) mainframe software program and Statistical Package for the Social Sciences 10.0 for Windows (SPSS). SPSS was used in the analysis of variance procedure to obtain estimates of effect size and statistical power.

The SPSS procedures employed for the analysis of subsequent course performance was the General Linear Model (GLM) with Univariate Analysis of Variance specified in the model statement. Cell sizes were unequal so Type III Sums of Squares method was used in the analysis of variance procedure. The four student groups (two remedial and two college-ready) were defined and entered as one of the independent variables. Race/ethnicity was coded into four groups and included as the other independent variable. Grades in first college-level courses were converted to numerical grade point average using the following rule: $\mathrm{A}=4.0 ; \mathrm{B}=3.0 ; \mathrm{C}=2.0 ; \mathrm{D}=1.0$; and $\mathrm{F}=$ 0.0. For the reading subject area, grades in all specified courses were combined to derive a grade point average for the relevant college-level courses for each student. These grade point averages served as the dependent variable. The alpha level set for each subject area 
hypothesis was $p<.05$. This procedure was executed for each of the three subject areas of reading, English, and mathematics.

With regard to the analysis of BSET impact on remedial course completion and success, the two remedial groups were defined and entered along with grades in the remedial courses. This chi-square procedure was executed for each of the three subject areas of reading, English, and mathematics. The alpha level set for each subject area hypothesis was $p<.05$.

To ascertain the relationship between BSET score and grades in subsequent college-level coursework for students enrolled Spring Term 1999-2000 who had successfully completed remediation the previous Fall Term, course grades were converted to numerical variables according to the following rule: $\mathrm{A}=4.0 ; \mathrm{B}=3.0 ; \mathrm{C}=$ $2.0 ; \mathrm{D}=1.0 ;$ and $\mathrm{F}=0.0 . \mathrm{BSET}$ score was entered along with course grade in the variable statement to obtain a Pearson Correlation Coefficient. This procedure was executed for each of the three subject areas and each of the four race/ethnic groups within the subject area. Correlations for race/ethnic groups with less than 30 students in a given subject area were not conducted. The alpha level was set at $p<.05$ for each test.

\section{Methodological Assumptions}

For the purposes of this study, it was assumed that the remedial course curriculum did not change during the time period covered, except as needed to ensure coverage of competencies tested by the BSET. It was assumed that minor modifications were made in response to the introduction of the BSET, and such modifications would be considered part of the overall impact of the BSET requirement. It was assumed that mastery expectations remained the same for assigning remedial course grades, limiting any 
differences in completion and success rates to the addition of the BSET requirement. Previous institutional research suggests that grade distributions vary somewhat by instructor, with some instructors being more lenient than others. It was assumed that the aggregation of grades across instructors would minimize the effect of individual differences in grading practices.

For the analysis of subsequent college-level course performance, it was assumed that grading practices and mastery recommendations remained the same for the first college-level courses included in the study during the time period covered. The researcher attempted to control for possible changes by including college-ready student cohorts enrolled in the same college-level courses, before and after the BSET, in the analysis.

It was further assumed that students in the remedial groups before and after the BSET had equivalent levels of academic preparation. All students were enrolled in the highest level remedial course due to CPT scores that fell within prescribed ranges for placement into the course, or as a result of passing the prerequisite remedial course. Therefore, all students included in the study could be assumed to be academically prepared for the highest level remedial course. The mathematics cohorts were further refined to ensure that the same CPT score ranges were used for placement before and after the BSET to ensure equivalent academic preparation levels.

Finally, students in the college-ready groups before and after the BSET were assumed to have equivalent skill levels. All of these students were placed into the course by CPT scores that attested to their readiness for the course. Again, the mathematics 
cohorts were refined to ensure that students' CPT scores fell within the same range before and after the BSET.

\section{Limitations}

The ex post facto design of this study imposed certain limitations on the study and its findings. Random assignment of students to groups or manipulation of independent variables was not possible. An attempt was made to control for independent variables that were likely to be related to the dependent variables such as race/ethnicity and entry level placement as measured by the CPT. In addition, an attempt was made to control for other factors (e.g. changes in grading practices, curriculum, or teaching style) that may be related to performance in college-level courses by including a comparison of results for college-ready students before and after the BSET implementation.

No statewide estimates of BSET reliability are available. Reliability was estimated based on administration of the exam at M-DCC. Poor reliability of the examinations is likely to affect the degree of impact the BSET has on remedial course completion and subsequent performance in college-level coursework.

The correlation analysis is limited in that only students with passing BSET scores $(60-100)$ are permitted to enroll in the college-level course in the subject area. For this reason, the correlation is not based on the full range of possible BSET scores and no information is available about the predictive utility of scores less than 60 .

Students enrolled in remedial coursework at any of the twenty-eight Florida community colleges or Florida Agricultural and Mechanical University (FAMU) are subject to the BSET requirement. This study is limited as it was restricted to Miami-Dade Community College students. The student population at Miami-Dade Community 
College differs in some respects from many of the other twenty-seven community colleges in the Florida Community College System. The proportion of minority students, particularly Hispanic students, is higher than the other community colleges (Division of Community Colleges, 2001). In addition, the proportion of students who need remediation, and the severity of that need, are somewhat more pronounced at M-DCC than at most of the other community colleges (Florida Department of Education, 2002). While these differences make M-DCC an ideal location for evaluating the impact of the BSET, particularly in respect to the impact on minority students, they may limit the extent to which results can be generalized.

This study explored the impact of the BSET on performance in the first collegelevel course in a subject area. No attempt was made to look at subsequent coursework in the same subject area or in any other subject areas. Additionally, only students who enrolled in the subsequent college-level course the following semester were included, so no information can be gleaned about the impact of the BSET on students who delay enrollment in the next course.

\section{Summary}

The research design and methodology applied in this study will enable the researcher to determine the impact of the BSET on remedial course completion and success, the predictive utility of BSET scores, and on student performance in subsequent college-level courses. The design will allow for determination of disproportionate impact on the ability of minority students to progress from remediation to college-level coursework. In summary, this study will indicate whether the BSET has created an additional barrier to students' access to higher education, and whether the BSET 
requirement appears to be justified by higher levels of academic readiness for collegelevel courses. 


\section{CHAPTER IV}

\section{ANALYSIS OF DATA AND FINDINGS}

This chapter presents the results of the statistical analyses conducted to test the six null Hypotheses, grouped by research question. The chapter begins with a description of the subjects included in the study populations for Hypotheses 1 and 2, which explore the impact of the BSET on subsequent college-level course performance; for Hypotheses 3 and 4, which analyze the impact of the BSET on remedial course completion and success; and for Hypotheses 5 and 6, which measure the relationship between BSET score and college-level course performance.

The description of subjects is followed by presentation of the results obtained for each of the Hypotheses grouped as indicated above. Interpretation of the results and decisions relative to each of the Hypotheses are given.

\section{Description of Subjects}

All of the students included in this study were enrolled as Associate in Arts or Associate in Science degree-seeking students at Miami-Dade Community College during Academic Years 1997-1998 or 1999-2000. In order to be included in the study, students also needed to be enrolled in one of several specific remedial and/or college-level courses and have CPT scores that were consistent with their course enrollment.

Subjects for Hypotheses 1 and 2

Students included as subjects for the analysis of performance in subsequent college-level courses met one of two criteria for selection and were grouped accordingly. To be included as remedial subjects, students had to have successfully completed the highest level remedial course in reading, English, or mathematics during Fall Term 1997- 
1998 or 1999-2000 and have enrolled in the next college-level course designated for the same subject area the following Spring Term. Additionally, students' CPT scores needed to be in the appropriate range for initial placement into remediation in the subject area. Students may have started in lower level remedial courses based on their CPT scores, but must have successfully completed the prerequisite remedial course(s) to be enrolled in the highest level course during the designated term.

To be included as college-ready subjects, students needed to have completed the first college-level course in the subject area during Spring Term 1997-1998 or 1999-2000 and have CPT scores that were high enough to be placed directly into the college-level course(s). Students who withdrew from, audited, or earned incompletes in the course(s) were not included in this analysis. Students with ACT or SAT scores that were used for course placement were not included in this analysis. Table 1 displays the number of students included for each subject area and grouping.

Table 1

Number of Students Included in Analysis of Performance in Subsequent College-Level Coursework

Group

Remedial

College-ready

Total

Subject

$1997-98$

1999-00

$1997-98$

$1999-00$

Reading

294

318

2,676

1,696

4,984

English

247

597

2,018

1,993

4,855

Mathematics

1,035

944

224

258

2,461 
Students included as subjects in the analysis of remedial course completion and success before and after the BSET requirement was introduced were enrolled in the highest level remedial course in reading, English, and/or mathematics during Fall Term 1997-1998 or Fall Term 1999-2000. Additionally, students' CPT scores had to be consistent with placement into remediation in that subject area. Students may have been placed into lower level remedial courses by their CPT scores, but must have successfully completed the prerequisite course(s) in order to be enrolled in the highest level course during the given terms. The few students who were auditing the remedial course, or who earned 'incompletes' for the course were not included. Table 2 displays the number of students included by subject area, term and ethnicity.

Table 2

Number of Students Included in Analysis of Remedial Course Completion and Success by Subject and Race/Ethnicity

Ethnicity

Subject

Black

Hispanic

White

Other $^{\mathrm{a}}$

Total

Fall 1997-98

$\begin{array}{lrrrrr}\text { Reading } & 196 & 528 & 78 & 16 & 818 \\ \text { English } & 207 & 408 & 67 & 13 & 695 \\ \text { Mathematics } & 1,025 & 2,127 & 440 & 52 & 3,644\end{array}$

Fall 1999-00

\begin{tabular}{lrrrrr} 
Reading & 595 & 1,251 & 130 & 42 & 2,018 \\
English & 552 & 1,152 & 107 & 32 & 1,843 \\
Mathematics & 1,030 & 2,111 & 385 & 45 & 3,571 \\
\hline
\end{tabular}

${ }^{a}$ Chi-square not conducted due to small number in this group. 
Subjects for Hypotheses 5 and 6

To be included in the analysis of the relationship between BSET score and subsequent college-level course performance students had to be enrolled in the highest level remedial course in the subject area during Fall Term 1999-2000, with CPT scores that were consistent with placement into remediation. Additionally, students had to have BSET scores on record for the subject area, and have been enrolled in the next collegelevel course(s) designated for the subject area during Spring Term 1999-2000. Table 3 displays the number of students included by subject area and race/ethnicity. More students were included in the mathematics subject area because a greater proportion of M-DCC students are required to take remedial mathematics than remedial English or reading. In addition, $\mathrm{M}-\mathrm{DCC}$ offers two different courses in mathematics that allow students to exit remediation in the subject area, as opposed to only one course sequence available to students in reading and English.

Table 3

Students Included in BSET/ Course Grade Correlation Race/ethnicity

\begin{tabular}{lccccc} 
Subject & Black & Hispanic & White & Other & Total \\
\hline Reading & 66 & 166 & $16^{\mathrm{a}}$ & $4^{\mathrm{a}}$ & 252 \\
English & 154 & 332 & 30 & $14^{\mathrm{a}}$ & 530 \\
Mathematics & 195 & 522 & 102 & $12^{\mathrm{a}}$ & 831 \\
\hline
\end{tabular}

\footnotetext{
${ }^{\text {a }}$ Correlations not conducted due to small number in cells.
} 


\section{Results}

\section{Tests for Hypotheses 1 and 2}

Null Hypothesis 1 states that there will be no significant difference between college-level course GPA for students who completed remediation after the BSET compared with students who completed remediation before the BSET. Null Hypothesis 2 states that there will be no significant difference between the college-level GPA of remedial students and college-ready students after the BSET. To test these Hypotheses, two-way analysis of variance was conducted for each of the three subject areas.

Reading results. One of the underlying assumptions regarding the use of ANOVA is that of equality of error variance across categories of the independent variables. Levene's Test of Equality of Error Variance is one way to evaluate this assumption. In this case the test results were significant, $F(15,4,968)=5.05, p<.01$, which means that the assumption was not met. Even though the $F$ value from the standard univariate ANOVA was significant for group membership, $F(3,4,983)=3.00, p<.05$, Tamhane's T2 was employed in the post-hoc analysis to evaluate Hypotheses 1 and 2 since this test does not assume equal variances. The difference between remedial groups in collegelevel course GPA was not significant $(p<.05)$. Therefore, null Hypothesis 1 is retained for the reading subject area. Students who completed remediation after the BSET did not have significantly higher mean grade point averages in subsequent college-level courses in the reading subject area than students who completed remediation before the BSET. Since M-DCC does not require students to take a college-level reading course, four general education courses with a strong reading component were included in this analysis 
of the reading subject area. Table 4 displays the ANOVA results and Table 5 displays the observed and adjusted sample means for reading

Table 4

Analysis of Variance for Reading Using Type III Sums of Squares

\begin{tabular}{lccccc} 
Source & $d f$ & $F$ & $\eta 2$ & $p$ & Power \\
\hline Group (G) & 3 & $3.00^{*}$ & .00 & .03 & .71 \\
Ethnicity (E) & 3 & .59 & .00 & .62 & .17 \\
G X E & 9 & 1.02 & .00 & .42 & .52 \\
$S$ within-group error & 4,968 & $(2.17)$ & & & \\
Total $d f$ & 4,983 & & & & \\
\hline
\end{tabular}

Note. Values enclosed in parentheses represent mean square errors. $S=$ subjects.

${ }^{*} p<.05$

Table 5

Observed and Adjusted Sample Means for Reading

\begin{tabular}{lccc} 
Group & $N$ & Observed & Adjusted \\
\hline Remedial Before BSET & 294 & 2.10 & 2.27 \\
Remedial After BSET & 318 & 2.17 & 2.22 \\
Ready Before BSET & 2,676 & 2.19 & 2.11 \\
Ready After BSET & 1,696 & 2.30 & 2.38 \\
Total & 4,984 & 2.22 & 2.24 \\
\hline
\end{tabular}

Tamhane's $T 2$ test also did not reveal a statistically significant difference between the remedial group and the college-ready group after the BSET. Table 5 displays the observed and adjusted means for the groups. Observed means were higher after the BSET 
for both the remedial and college-ready groups, but these differences were not statistically significant. Adjusted sample means show a slight decline in remedial student GPA after the BSET while the college-ready student GPA increased. Since these differences were not statistically significant, null Hypothesis 2 is retained. There was no significant difference between remedial and college-ready student mean grade point averages in the related college-level courses after the introduction of the BSET.

English results. In this analysis, the equality of error variance assumption for ANOVA was not met. Levene's Test of Equality of Error Variance was significant, $F(15$, $4,839)=7.38, p<.01$. Tamhane's $T 2$ was employed in the post-hoc analysis of Hypotheses 1 and 2 for the English subject area, since this test does not assume equal variances. Test results did not reveal any significant difference between the remedial groups before and after the BSET was introduced, although there was a statistically significant difference in mean grade point average between several pairs of race/ethnic groups at the $p<.05$ level. Although there was a significant main effect for ethnicity, there was no significant interaction effect between ethnicity and group. Therefore, these ethnic differences appear to be unrelated to the BSET.

Based on these results, null Hypothesis 1 is retained. There was no significant increase in mean grade point average for remedial students after the BSET was introduced. Null Hypothesis 2 is also retained for the English subject area. There was no significant difference between remedial and college-ready student performance in college-level courses after the BSET. Table 6 displays the univariate results for English, Table 7 displays the observed and adjusted means by group, and Table 8 displays the observed and adjusted means by ethnicity. 
Table 6

Analysis of Variance for English Using Type III Sums of Squares

\begin{tabular}{lrrrrr} 
Source & $d f$ & $F$ & $\eta 2$ & $p$ & Power \\
\hline Group (G) & 3 & 1.31 & .00 & .27 & .35 \\
Ethnicity (E) & 3 & $6.33^{*}$ & .00 & .01 & .82 \\
G X E & 9 & 1.62 & .00 & .10 & .76 \\
$\begin{array}{l}S \text { within-group } \\
\text { error }\end{array}$ & 4,839 & $(1.67)$ & & & \\
Total $d f$ & 4,854 & & & & \\
\hline
\end{tabular}

Note. Values enclosed in parentheses represent mean square errors. $S=$ subjects.

${ }^{*} p<.05$

Table 7

Observed and Adjusted Sample Means for English by Group

\begin{tabular}{lccc} 
Group & $N$ & Observed & Adjusted \\
\hline Remedial Before BSET & 247 & 2.00 & 1.99 \\
Remedial After BSET & 597 & 2.04 & 2.11 \\
Ready Before BSET & 2,018 & 2.03 & 2.24 \\
Ready After BSET & 1,993 & 1.99 & 2.13 \\
Total & 4,855 & 2.01 & 2.12 \\
\hline
\end{tabular}


Table 8

Observed and Adjusted Sample Means for English by Ethnicity

\begin{tabular}{lccc} 
Ethnicity & $N$ & Observed & Adjusted \\
\hline Asian/Other & 109 & 2.39 & 2.24 \\
Black non-Hispanic & 1,052 & 1.98 & 1.98 \\
Hispanic & 3,097 & 1.94 & 1.98 \\
White non-Hispanic & 597 & 2.36 & 2.27 \\
Total & 4,855 & 2.01 & 2.12 \\
\hline
\end{tabular}

Mathematics results. The assumption of equality of error variances is met for the mathematics subject area, based on the results of Levene's Test of Equality of Error Variances, $F(15,2,445)=1.15, p=.31$. Therefore, the standard analysis of variance results were used to test null Hypotheses 1 and 2 for this subject area. The analysis of variance revealed no significant main or interaction effects at the $p<.05$ level. Table 9 displays univariate results for mathematics.

Table 9

Analysis of Variance for Mathematics Using Type III Sums of Squares

\begin{tabular}{lccccc} 
Source & $d f$ & $F$ & $\eta 2$ & $p$ & Power \\
\hline Group (G) & 3 & .29 & .00 & .83 & .11 \\
Ethnicity (E) & 3 & 1.40 & .00 & .24 & .38 \\
G X E & 9 & 1.60 & .00 & .11 & .76 \\
$S$ within-group error & 2,445 & $(1.97)$ & & & \\
Total $d f$ & 2,460 & & & & \\
\hline
\end{tabular}

Note. Values enclosed in parentheses represent mean square errors. $S=$ subjects. 
Examination of observed means for the remedial and college-ready groups revealed an increase in mean grade point average for remedial students and college-ready students after the BSET, but these increases were not statistically significant. Therefore, null Hypothesis 1 is retained. There was no significant increase in mean grade point average in college-level courses for remedial students after the BSET. Null Hypothesis 2 is also retained. There was no significant difference in mean grade point average in college-level courses between remedial and college-ready groups after the BSET. Table 10 displays the observed and adjusted means for mathematics.

Table 10

Observed and Adjusted Sample Means for Mathematics

\begin{tabular}{lccc} 
Group & $N$ & Observed & Adjusted \\
\hline Remedial Before BSET & 1,035 & 1.51 & 1.69 \\
Remedial After BSET & 944 & 1.59 & 1.72 \\
Ready Before BSET & 224 & 1.50 & 1.58 \\
Ready After BSET & 258 & 1.63 & 1.58 \\
Total & 2,461 & 1.55 & 1.64 \\
\hline
\end{tabular}

Tests for Null Hypotheses 3 and 4

Null Hypotheses 3 states that there will be no significant relationship between remedial course completion and success rates and the BSET requirement. Null Hypothesis 4 further states that there will be no significant relationship for minority students. To test these Hypotheses, chi-square analysis was conducted on student grades in remedial courses before and after the BSET for the total group of students and for each ethnic group. Due to small cell sizes, chi-square results are not reported for ethnic groups 
with less than 50 students in a given cohort. An alpha level of .05 was used to test both hypotheses.

Reading results. There is a relationship between remedial course grades and the BSET requirement in the reading subject area, $\chi^{2}(3, N=2,836)=19.15, p<.01$, for the total group of students. Upon further analysis by ethnicity, only the Hispanic minority group showed this strong relationship, $\chi^{2}(3, N=1,779)=18.38, p<.01$. This relationship was absent with other minority ethnic groups for the reading subject area.

Based on these results, null Hypothesis 3 is rejected. There was a significant relationship between remedial reading course grades and the BSET requirement for the total student group. Inspection of grade distributions indicates that students were more likely to earn $U$ (unsatisfactory progress) grades after the introduction of the BSET (12\%) compared with students before the BSET (7\%).

Null Hypothesis 4 is also rejected. There was a statistically significant relationship between remedial reading course grades and the BSET requirement for minority students. Specifically, inspection of the grade distribution indicates that Hispanic students were more likely to earn U (unsatisfactory progress) grades after the BSET requirement was introduced. Tables 11 through 14 display chi-square results and grade distributions for reading.

English results. Chi-square analysis did not reveal a significant relationship at the $p<.05$ level between grades in the remedial English course and the BSET requirement for the total group or any ethnic group.

Based on these results, null Hypotheses 3 and 4 are retained for the English subject area. There was no significant relationship between remedial English course 
Table 11

Reading Grade Distribution for Total Group*

Grade

\begin{tabular}{lcccc} 
Cohort & S & PR & U & W \\
\hline Before BSET & $65 \%$ & $20 \%$ & $7 \%$ & $8 \%$ \\
After BSET & $63 \%$ & $15 \%$ & $12 \%$ & $9 \%$ \\
\hline
\end{tabular}

Note. Total group includes 58 Asian and 'Other' minority students.

$\mathrm{S}=$ Satisfactory $/$ passing; $\mathrm{PR}=$ Progress but not passing; $\mathrm{U}=$ Unsatisfactory progress; $\mathrm{W}=$ Withdrawal.

${ }^{*} \chi^{2}(3, N=2,836)=19.15, p<.01$

Table 12

Reading Grade Distribution for Black non-Hispanics*

Grade

\begin{tabular}{lcccc} 
Cohort & S & PR & U & W \\
\hline Before BSET & $58 \%$ & $24 \%$ & $7 \%$ & $11 \%$ \\
After BSET & $61 \%$ & $19 \%$ & $10 \%$ & $10 \%$ \\
\hline
\end{tabular}

Note. $\mathrm{S}=$ Satisfactory $/$ passing; $\mathrm{PR}=$ Progress but not passing; $\mathrm{U}=$ Unsatisfactory progress; $\mathrm{W}=$ Withdrawal.

${ }^{*} \chi^{2}(3, N=791)=4.45, p=.22$

Table 13

Reading Grade Distribution for Hispanics*

Grade

\begin{tabular}{lcccc} 
Cohort & S & PR & U & W \\
\hline Before BSET & $67 \%$ & $19 \%$ & $7 \%$ & $7 \%$ \\
After BSET & $64 \%$ & $14 \%$ & $13 \%$ & $9 \%$ \\
\hline
\end{tabular}

Note. $\mathrm{S}=$ Satisfactory $/$ passing; $\mathrm{PR}=$ Progress but not passing; $\mathrm{U}=$ Unsatisfactory progress; $\mathrm{W}=$

Withdrawal.

${ }^{*} \chi^{2}(3, N=1,779)=18.38, p<.01$ 
Table 14

Reading Grade Distribution for White non-Hispanics*

Grade

\begin{tabular}{lcccc} 
Cohort & S & PR & U & W \\
\hline Before BSET & $65 \%$ & $18 \%$ & $9 \%$ & $8 \%$
\end{tabular}

\begin{tabular}{lcccc} 
After BSET & $62 \%$ & $17 \%$ & $13 \%$ & $8 \%$ \\
\hline Note. $\mathrm{S}=$ Satisfactory $/$ passing; $\mathrm{PR}=$ Progress but not passing; $\mathrm{U}=$ Unsatisfactory progress; $\mathrm{W}=$
\end{tabular} Withdrawal.

${ }^{*} \chi^{2}(3, N=208)=.89, p=.83$

grades and BSET requirement for the total group or for any minority ethnic group studied. Inspection of grade distributions indicates that students were somewhat less likely to earn S (Satisfactory/passing) grades after the BSET was introduced (53\% vs. $57 \%$ for the total group and $54 \%$ vs. $62 \%$ for Hispanic students), but these differences in proportion were not significant. Tables 15 through 18 display chi-square results and grade distributions for English.

Table 15

English Grade Distribution for Total Group*

Grade

\begin{tabular}{lcccc} 
Cohort & S & PR & U & W \\
\hline Before BSET & $57 \%$ & $26 \%$ & $10 \%$ & $7 \%$ \\
After BSET & $53 \%$ & $27 \%$ & $12 \%$ & $8 \%$ \\
\hline
\end{tabular}

Note. Total group includes 45 Asian and 'Other' minority students. $\mathrm{S}=$ Satisfactory/passing; PR = Progress but not passing; $\mathrm{U}=$ Unsatisfactory progress; $\mathrm{W}=$ Withdrawal.

${ }^{*} \chi^{2}(3, N=2,538)=5.49, p=.14$ 
Table 16

English Grade Distribution for Black non-Hispanics *

Grade

\begin{tabular}{lcccc} 
Cohort & S & PR & U & W \\
\hline Before BSET & $48 \%$ & $37 \%$ & $10 \%$ & $5 \%$ \\
After BSET & $48 \%$ & $35 \%$ & $10 \%$ & $7 \%$ \\
\hline
\end{tabular}

Note. $\mathrm{S}=$ Satisfactory $/$ passing; $\mathrm{PR}=$ Progress but not passing; $\mathrm{U}=$ Unsatisfactory progress; $\mathrm{W}=$ Withdrawal.

${ }^{*} \chi^{2}(3, N=759)=1.13, p=.77$

Table 17

English Grade Distribution for Hispanics*

Grade

\begin{tabular}{|c|c|c|c|c|}
\hline Cohort & $\mathrm{S}$ & PR & $\mathrm{U}$ & W \\
\hline Before BSET & $62 \%$ & $20 \%$ & $11 \%$ & $8 \%$ \\
\hline After BSET & $54 \%$ & $24 \%$ & $13 \%$ & $9 \%$ \\
\hline \multicolumn{5}{|c|}{$\begin{array}{l}\text { Note. } \mathrm{S}=\text { Satisfactory/passing; } \mathrm{PR}=\text { Progress but not passing; } \mathrm{U}=\text { Unsatisfactory progress; } \mathrm{W}= \\
\text { Withdrawal. } \\
{ }^{*} \chi^{2}(3, N=1,560)=7.72, p=.05\end{array}$} \\
\hline \multicolumn{5}{|l|}{ Table 18} \\
\hline English Grad & a for $W$ & Hispani & & \\
\hline
\end{tabular}

Grade

\begin{tabular}{lcccc} 
Cohort & S & PR & U & W \\
\hline Before BSET & $58 \%$ & $24 \%$ & $10 \%$ & $7 \%$ \\
After BSET & $59 \%$ & $21 \%$ & $10 \%$ & $10 \%$ \\
\hline
\end{tabular}

Note. $\mathrm{S}=$ Satisfactory $/$ passing; $\mathrm{PR}=$ Progress but not passing; $\mathrm{U}=$ Unsatisfactory progress; $\mathrm{W}=$ Withdrawal.

${ }^{*} \chi^{2}(3, N=174)=.57, p=.90$ 
Mathematics results. Chi-square analysis revealed a significant relationship between remedial mathematics course grades and the BSET for the total group, $\chi^{2}(3, N=$ $7,215)=46.20, p<.01$. Significant relationships were also observed for Black nonHispanics, $\chi^{2}(3, N=2,055)=17.72, p<.01$, and for Hispanic students, $\chi^{2}(3, N=4,238)$ $=25.16, p<.01$.

Based on these results, null Hypothesis 3 is rejected for the mathematics subject area. Grade distribution for the mathematics area revealed that a smaller proportion of students earned S (Satisfactory/passing) grades after the BSET. Null Hypothesis 4 is also rejected. There was a significant relationship between remedial mathematics course completion and success as evidenced by final course grades and the BSET for Black nonHispanic and Hispanic students. Inspection of grade distributions for the remedial mathematics courses indicates that both Black non-Hispanic and Hispanic students were less likely to earn S (Satisfactory/passing) grades after the introduction of the BSET. Tables 19 through 22 display chi-square results and grade distributions for mathematics. Table 19 Mathematics Grade Distribution for Total Group*

Grade

\begin{tabular}{lcccc} 
Cohort & S & PR & U & W \\
\hline Before BSET & $48 \%$ & $21 \%$ & $22 \%$ & $9 \%$ \\
After BSET & $40 \%$ & $25 \%$ & $24 \%$ & $10 \%$ \\
\hline
\end{tabular}
Note. Total group includes 97 Asian and 'Other' minority students. $\mathrm{S}=$ Satisfactory/passing; $\mathrm{PR}=$ Progress but not passing; $\mathrm{U}=$ Unsatisfactory progress; $\mathrm{W}=$ Withdrawal.

${ }^{*} \chi^{2}(3, N=7,215)=46.20, p<.01$ 
Table 20

Mathematics Grade Distribution for Black non-Hispanics*

Grade

\begin{tabular}{lcccc} 
Cohort & S & PR & U & W \\
\hline Before BSET & $40 \%$ & $23 \%$ & $27 \%$ & $10 \%$ \\
After BSET & $31 \%$ & $29 \%$ & $29 \%$ & $11 \%$ \\
\hline
\end{tabular}

Note. $\mathrm{S}=$ Satisfactory $/$ passing; $\mathrm{PR}=$ Progress but not passing; $\mathrm{U}=$ Unsatisfactory progress; $\mathrm{W}=$ Withdrawal.

${ }^{*} \chi^{2}(3, N=2,055)=17.72, p<.01$

Table 21

Mathematics Grade Distribution for Hispanics*

Grade

Cohort

Before BSET

After BSET

Note. $\mathrm{S}=$ Satisf

Withdrawal.

${ }^{*} \chi^{2}(3, N=4,238)=25.16, p<.01$

Table 22

Mathematics Grade Distribution for White non-Hispanics*

Grade

\begin{tabular}{lcccc} 
Cohort & S & PR & U & W \\
\hline Before BSET & $53 \%$ & $20 \%$ & $18 \%$ & $9 \%$ \\
After BSET & $47 \%$ & $24 \%$ & $18 \%$ & $11 \%$ \\
\hline
\end{tabular}

Note. $\mathrm{S}=$ Satisfactory $/$ passing; $\mathrm{PR}=$ Progress but not passing; $\mathrm{U}=$ Unsatisfactory progress; $\mathrm{W}=$ Withdrawal.

${ }^{*} \chi^{2}(3, N=825)=4.34, p=.23$ 
Hypothesis 5 states that there will be no significant relationship between BSET score and subsequent college-level course GPA in each of the reading, English, and mathematics subject areas. Hypothesis 6 further states that there will be no significant relationship for minority students. Correlations between BSET score and subsequent GPA in the three subject areas were computed to test these Hypotheses. Using an alpha level of .05 , significant correlations were found for all three of the subject areas. The strongest relationship was observed for mathematics, $r(831)=.45, p<.01$; followed by English, $r(530)=.21, p<.01$, and then reading, $r(252)=.13, p<.05$. Table 23 displays descriptive statistics obtained in the correlation analysis. Table 24 displays correlations by subject area for each race/ethnicity as well as the total cohort.

Table 23

Descriptives From Correlation Analysis by Subject Area

\begin{tabular}{lccccc} 
Variable & $N$ & $M$ & $S D$ & Min & Max \\
\hline & & & Reading & \\
BSET & 252 & 75.36 & 7.54 & 61 & 94 \\
GPA & 252 & 2.16 & 1.34 & 0 & 4 \\
& & & English & & \\
BSET & 530 & 73.44 & 7.85 & 60 & 98 \\
GPA & 530 & 2.08 & 1.09 & 0 & 4 \\
& & & Mathematics & & \\
BSET & 831 & 78.71 & 10.44 & 60 & 100 \\
GPA & 831 & 1.64 & 1.41 & 0 & 4 \\
\hline
\end{tabular}


Table 24

Correlations Between BSET Score and Grade by Subject Area and Racelethnicity

Race/Ethnicity

\begin{tabular}{lcccc} 
Subject & Black & Hispanic & White & Total \\
\hline Reading & .00 & .14 & -- & $.13^{*}$ \\
English & $.26^{*}$ & $.16^{*}$ & .06 & $.21^{*}$ \\
Mathematics & $.34^{*}$ & $.46^{*}$ & $.55^{*}$ & $.45^{*}$ \\
\hline
\end{tabular}

$* p<.05$

Reading results. There was a significant relationship between the BSET reading score and college-level course GPA for the total group of students $(p<.05)$, but not for any race/ethnic group taken separately. In addition, there was no correlation at all between BSET reading score and college-level course grades for Black non-Hispanic students. Therefore, null Hypothesis 5 is rejected in the reading subject area for the total group of students, but null Hypothesis 6 is retained for all individual ethnic minority groups. There was a statistically significant relationship between BSET reading score and GPA in related college-level courses for the total group of students, but not for minority students.

English results. The correlations between BSET English score and English grade were positive and significant $(p<.05)$ for the total group of students and for minority students. Therefore, null Hypothesis 5 is rejected for the total group of students. Null Hypothesis 6 is also rejected. There was a statistically significant relationship between BSET English score and grades in college-level English courses for the total group of students, Black non-Hispanic students, and Hispanic students. 
Mathematics results. There was a positive relationship between BSET

mathematics score and college-level mathematics course grades for the total group of students and for all ethnic groups. All correlations were significant at $p<.05$. Therefore, null Hypothesis 5 is rejected for the mathematics subject area and null Hypothesis 6 is also rejected. In other words, there was a significant positive relationship between BSET mathematics score and grades in college-level mathematics courses for the total group of students as well as for Black non-Hispanic, Hispanic, and White non-Hispanic students separately.

\section{Summary}

Based on the results of this analysis the BSET appeared to have no impact on subsequent college-level course performance in any of the three subject areas of reading, English, or mathematics. Students who completed remediation before the BSET requirement were just as likely to be successful in subsequent college-level courses than students who completed remediation after the BSET requirement. In addition, differences in performance between remedial and college-ready students were not altered significantly by the introduction of the BSET as an additional measure of student readiness for subsequent college-level coursework.

In spite of the lack of positive impact on subsequent college-level course performance, the BSET requirement did appear to negatively impact the likelihood that students would pass remedial reading and mathematics courses. Students were less likely to successfully complete reading and mathematics remediation after the BSET requirement was introduced. In particular, Hispanic students were more likely to receive failing grades in reading after the introduction of the BSET. In mathematics, Black non- 
Hispanic and Hispanic students were more likely to receive failing grades, and therefore less likely to progress to college-level mathematics courses after the introduction of the BSET.

There was a positive relationship between BSET score and subsequent collegelevel course performance for all of the three subject areas, although the relationship was somewhat weak for the reading subject area $(r=.13)$, and only moderate for the English subject area $(r=.21)$. These relationships varied by student ethnicity. For example, there was no relationship at all between BSET reading score and subsequent course performance for Black non-Hispanic students. In contrast, the relationship between BSET English score was significant and positive for Black non-Hispanic and Hispanic students, but not for White non-Hispanic students. The relationship between BSET mathematics score and subsequent course performance was significant and positive for all ethnic groups. 


\section{CHAPTER V \\ DISCUSSION}

This chapter begins with an overall summary of the study, followed by a discussion of the findings and results. The current study is discussed in the context of the literature related to public policy and high-stakes testing following the themes presented in Chapter II: a) high-stakes tests for education reform and accountability; b) public policy and the use of tests in Florida with a discussion on the use of the BSET at M-DCC; and c) the positive and negative consequences of high-stakes tests. The chapter concludes with recommendations for future research and policy implications of the findings.

\section{Summary of the Study}

This study explored the impact of one of the high-stakes tests currently mandated by the State of Florida (the Basic Skills Exit Test) on remedial student progress and subsequent student performance. The BSET was introduced as a means of improving remedial instruction and providing a measure of accountability through the imposition of student learning objectives. The intent was to enhance the effectiveness of community college remedial programs in preparing students to be successful in subsequent collegelevel coursework. The ever-increasing number of students entering college in need of remediation, and associated State of Florida expenditures for such remediation, led to the mandate to administer an accountability examination.

This study examined the impact of the BSET on M-DCC students' likelihood of successfully completing remediation and evaluated whether demonstrated mastery of skills, as measured by the BSET, is meaningful in terms of predicting later success in 
college-level courses. The specific research questions, which guided this study are as follows:

1. To what extent has the state-mandated BSET improved college readiness of students who completed remedial coursework at Miami-Dade Community College as measured by differences in GPA in first collegelevel courses before and after introduction of the BSET requirement?

2. To what extent has the state-mandated BSET improved college readiness of students at Miami-Dade Community College as measured by differences in performance of remedial coursework completers compared with college-ready students before and after the introduction of the BSET (is there a performance gap between remedial and college-ready students before and after the introduction of the BSET)?

3. To what extent has the BSET affected remedial course completion and success rates at Miami-Dade Community College?

4. Is there a relationship between BSET score and subsequent performance in college-level courses at Miami-Dade Community College?

5. To what extent do these relationships vary by subject area and race/ethnicity?

This study tested six hypotheses addressing these research questions. The dependent measures were grade point average in college-level courses and grades in remedial courses. The hypotheses were tested using two-way analysis of variance, chisquare analysis, and correlation analysis. 


\section{Compilation of Findings}

The following summarizes the findings of the study:

1. There was no significant difference between the college-level course performance of students who completed remediation before and after the BSET for the total group of students or for minority students.

2. There was no significant difference between the performance of students who completed remediation and college-ready students after the BSET was introduced.

3. There was a significant decrease in students' likelihood of passing remedial reading and mathematics courses after the BSET was introduced. There was no significant difference for the English courses.

4. There was a significant decrease in minority students' likelihood of passing remedial reading and mathematics courses after the BSET was introduced. Hispanic students were less likely to pass remedial reading after the BSET. Black non-Hispanic and Hispanic students were less likely to pass remedial mathematics courses after the BSET. There was no significant difference for the English courses.

5. There was a significant positive relationship between BSET score and subsequent college-level course performance for reading, English, and mathematics.

6. The relationship between BSET score and subsequent college-level course performance varied by ethnicity. There was no significant relationship between BSET reading score and subsequent course performance for 
Black non-Hispanic students. In addition, for White non-Hispanic students, the relationship between BSET score and subsequent course performance was significant in the mathematics subject area only.

\section{Discussion}

This study revealed an important unexpected finding: The reliability of the BSET as measured by indices of internal consistency at M-DCC is unacceptably low. Reliability estimates ranged from .41 for the reading examination to .79 for the mathematics examination, all well below Nunnally's recommended minimum level of .90 for highstakes examinations (Nunnally, 1978). These unacceptably low levels of reliability may have contributed to the lack of impact on subsequent course performance found in this study, limiting the utility of the results in providing information on the validity of the BSET. The reliability levels may also limit the extent to which the results can be interpreted relative to the literature. On the other hand, this discovery, coupled with the lack of established reliability and validity at the state level for the BSET, provides insight into the potential liability of employing tests for education reform.

High-Stakes Tests for Education Reform and Accountability

As stated previously, high stakes testing programs are popular tools for policy makers who wish to improve instruction and achievement. Since they often cannot directly impact instructional practice, policy makers frequently resort to mandating testing programs to do this work for them. The reasoning is that if students are denied access to diplomas or advancement to the next educational level, changes will occur within institutions to enhance student achievement, and at the student level by strengthening study habits and resolve to succeed (Airasian \& Madaus, 1983, p. 108). 
Too often, however these high-stakes examinations are mandated with little established validity for their intended purpose and minimal subsequent evaluation of consequences. The public is subjected to these high-stakes examination requirements with little evidence that they will achieve their intended purpose. While the literature abounds with recommendations about how validity studies and evaluations of high-stakes examinations should be conducted, there is an unfortunate scarcity of actual validity or impact studies reported.

This may attest to the strength of the symbolic value of high-stakes examinations. Madaus and Kellaghan (1983) suggest that if the results of examinations are believed to be important, then the actual value of the results matters little. It is the perception of value that counts for teachers, administrators, students and policy makers. Teachers and administrators may be skeptical initially, but are likely to become advocates for the test if they observe students' scores increasing after revising instructional strategies to better prepare for the test. According to this line of reasoning, if test scores increase, it seems to matter little if the scores represent valid measures of student achievement or generalize beyond the test itself.

Policy makers appear to have confidence in the tests to improve educational outcomes and merely have to look to other state or federal policy makers to see that their confidence is shared by colleagues. With the widespread call for state and national highstakes testing, the value of the tests seems to be taken for granted. Finally, students begin early in their educational experience to gauge what is important in the curriculum by what will appear on the test. Therefore, students are likely to accept testing as part of the educational process and may be less likely to question what the results really mean. 
Given this, it is no surprise that after developing and introducing an examination, there is often little evaluation conducted to discern the impact and effectiveness of the examination. The Basic Skills Exit Test appears to be an example of just such a case.

This study followed guidelines set forth in the literature in evaluating the impact of the BSET. The design of the study allowed for an analysis of the potential positive effect of enhanced student performance in college-level courses. The study also evaluated the possible negative impact on students' ability to successfully complete remedial coursework and progress to college-level coursework. By including race/ethnicity in the analysis, the impact of the BSET on minority students was also evaluated. The intended and unintended consequences, the positive and negative effects, all should be weighed when determining whether a high-stakes test is producing better education outcomes (Heubert \& Hauser, 1999, p. 172). This study provides evidence of just such effects and consequences for the BSET.

The findings of this study indicate that the BSET had no discernable positive effect on student preparation for college-level coursework. The BSET has not raised standards in the remedial programs, encouraged higher student achievement, or ensured better curricular alignment or instructional strategies that might have resulted in an increase in college-level success rates for remedial completers. Moreover, the results indicate that the BSET had a negative impact on student progression through the remedial coursework. A smaller proportion of students passed remedial reading and mathematics courses after the introduction of the BSET. This was particularly true for minority students, who apparently suffered the most due to the BSET requirement. 
Kane (2002), in a discussion about the policy assumptions underlying testing programs, writes that much of the current practice of validating high-stakes testing programs is seriously flawed. He explains that only part of the interpretive argument is evaluated (p. 40). Validity evidence tends to emphasize inferences from the test scores to the standards or desired outcomes, without any real data to support such an inference. In other words, are decisions made on the basis of test scores justified? What evidence do we have that a test score actually reflects a student's knowledge in the subject area and is that knowledge meaningful in other contexts?

One of the policy assumptions underlying the BSET is that the examinations are effective in measuring educational objectives for the subject area. With calculated reliability estimates at M-DCC ranging from .41 to .79 , this assumption does not appear to be met. Another assumption is that mastery of the objectives or competencies defined for the subject area is critical to success in subsequent college-level coursework in the subject area. This assumption is questionable given the results of this study, particularly for the reading subject area. With correlations between BSET score and subsequent course performance as low as .13 for reading, .21 for English, and .45 for mathematics, one must question the inherent value of the BSET in predicting performance. When evaluating this assumption, it is particularly important to evaluate for different types of students who will be subject to the test requirement.

For example, there was no relationship between the BSET reading score and subsequent course performance for Black non-Hispanic students. The BSET had no predictive validity for this minority student group although a relationship existed for the total student group and for other race/ethnic groups. If the relationship had not been 
explored for each race/ethnic group, one would conclude that the BSET was useful in predicting performance for students at M-DCC. Upon further analysis, it is clear that this is not true for subgroups of students such as Black non-Hispanic students in the reading subject area. This distinction is important when evaluating the validity and fairness of using the BSET to make important decisions about students.

Another assumption underlying the BSET is that the imposition of this testing requirement would result in remedial programs that are more effective in preparing students for the rigor of subsequent coursework. Given the results of this study, this assumption has not been met. Students are no more likely to be successful in subsequent coursework if they completed remediation after the BSET requirement was introduced than they were prior to the requirement. In addition, where differences existed between the performance of college-ready students and students who completed remediation, those differences remained after the BSET was introduced. The BSET has not had any noticeable impact on the effectiveness of remedial programs at M-DCC to prepare students for subsequent college-level coursework.

Public Policy and the Use of Tests in Florida

As discussed previously, the State of Florida has a long history of mandating testing programs as a way of stimulating educational reform and encouraging higher student achievement. The College Level Academic Skills Test (CLAST) was introduced to ensure that students attained the skill levels considered necessary for success in upper division coursework. Even though the relationship between these skill levels and subsequent success in upper division coursework has never been established, the CLAST continues to be required. 
The BSET is somewhat unique in that some of the control is given to individual institutions to set passing scores and administration guidelines. Nevertheless, the BSET is compulsory. Colleges must administer the examination following the blueprint and using the items developed by the State. Students are required to pass the examination to advance to college-level coursework, but no state-level evaluation of the appropriateness of such progression decisions has been conducted. Perhaps the BSET is serving one speculative purpose - the symbolic value of having a test in place to insure that remedial students meet established learning objectives and assure policy makers of a return on the State's investment in remedial education. But this assurance means little if student performance in subsequent coursework has not improved after the BSET requirement. The BSET Requirement at Miami-Dade Community College

Initial passing scores were established at M-DCC for the BSET examinations based on pilot test results. Scores were set to most closely mirror the grading practices of faculty. An attempt was made to minimize the number of students to whom faculty would assign passing grades who would fail the course as a result of their BSET score. In reading and English, this also had the effect of assigning passing BSET performance to the majority of students to whom faculty would have assigned a failing grade. Since students need to pass the coursework and the BSET to successfully pass the course, these students were not permitted to progress to the next level. Even so, this raises at least two questions: a) Is the passing score for reading and English set at an appropriate level if it fails to discriminate well between students who faculty determined to be passing and those determined to be failing the coursework? b) How effective is the test itself in discriminating between better and poorer students on the objectives covered by the test? 
Given the low reliability estimates for the reading and English BSET

examinations, the test itself may be a poor measure of student achievement. The passing score of $60 \%$ for the mathematics BSET appeared to discriminate between better and poorer students to a greater extent than the reading and English examinations. Additional evaluation of the examinations and passing score levels at M-DCC is certainly needed in order to justify their use in decisions affecting student success and progression. Negative Consequences

The passing score levels set at M-DCC, particularly in the reading and English subject areas, may also contribute to an unintended negative consequence of the BSET. Correlations between reading and English BSET scores and subsequent course performance were relatively low (.13 and .21 respectively). It may be the case that students knew they only needed $60 \%$ to pass the examination and expended effort accordingly. Students who were otherwise able to perform better may have put minimal effort into the examination and achieved a lower score than they could have earned. This would have influenced the observed relationship between BSET score and subsequent performance. Linn (1998) determined that high-stakes tests can de-motivate highachieving students since the minimum level of knowledge needed to pass the test becomes all they believe they need to know.

In focus groups conducted with remedial students in Fall Term 2001 at M-DCC, students expressed views consistent with Linn's finding. Many of the students stated that the $60 \%$ level was not difficult to attain and that they thought that level of knowledge was adequate to be successful in subsequent college-level coursework. When discussing their perceived preparation for the subsequent college-level course, the students were 
disappointed and felt misled. They thought that passing the remedial coursework and the BSET at the $60 \%$ passing score level was an indication that they were well prepared for the next course. Many of the students discovered that their confidence was unfounded as they struggled in the next course (M-DCC Enrollment Management Committee, personal communication, 2002).

Another potential negative consequence cited by Linn (1998) is the possibility that high-stakes examinations will discourage lower performing students. If this were true, we might expect to have seen an increase in students withdrawing from the remedial courses after the BSET. This result was not observed in this study. For each subject area the percentage of students withdrawing from the course increased by only one percentage point.

Lewis (2000) cautioned that high-stakes examinations may have a disparate effect on minority students' retention and success. In the analysis of remedial course completion and success conducted as part of this study, Hispanic students were more likely to fail the remedial reading course after the BSET was introduced, while no significant difference was observed for other ethnic groups. In the mathematics subject area, both Black non-Hispanic and Hispanic students were more likely to fail after the BSET, suggesting that the impact of the BSET was greater for minority students. This is a troublesome finding, given the emphasis placed on minority student access and opportunity at the community college level. Additional evaluation of the validity of the BSET and its impact on minority students' progression and success is warranted. 


\section{Positive Consequences}

As mentioned previously, the BSET was intended to certify student readiness for college-level coursework and enhance student success in such coursework. The results of this study do not indicate that the BSET is serving this purpose. Student performance in subsequent coursework has not improved since the BSET was introduced. While observed remedial student mean grade point average increased in college-level mathematics courses and general education courses with a heavy reading component, so did the grade point averages of college-ready students. Although these increases were not statistically significant, further study may be warranted to determine the likely cause of the increases. The curriculum for these college-level courses was not changed during the time period covered by this study, so other factors are likely to have contributed to these increases. Some possibilities include improved instructional strategies in the college-level courses, and simple grade inflation by faculty who feel pressure to pass students.

No significant increases in grade point averages were detected after the BSET.

Given the poor reliability of the BSET, these results could be due to the psychometric properties of the examinations themselves, or reflect a real lack of impact on subsequent student performance. If the latter were true, it could mean that the skills identified as necessary for success in subsequent college-level courses are, in fact, not predictive of success. Students may not need to master these skills prior to progressing. Rather, they may be able to acquire the skills later while tackling more advanced material in subsequent courses as the cognitive learning proponents assert (Frederikson, Mislevy, \& Bejar, 1993; Glaser \& Silver, 1994; Shepard, 1991). 


\section{Conclusions}

The BSET has had no noticeable positive effect on remedial student performance in subsequent college-level courses. In other words, the BSET has not enhanced the effectiveness of the remedial programs to prepare students for later coursework at MiamiDade Community College. This finding is consistent with reported studies in the literature indicating that high-stakes test results do not generalize well to other settings (Klein, Hamilton, McCaffrey, \& Stecher, 2000; Haertel, 1999)

The BSET has had a negative impact on the progress and success of students in remedial reading and mathematics. This finding is particularly true for minority students who are less likely to pass the remedial courses after the BSET was introduced. These findings of disparate impact on minority students are consistent with studies reported in the literature on high-stakes tests (Garcia, 1995; Natriello \& Pallas, 1998).

The reliability of the BSET examinations at M-DCC is unacceptably low and warrants immediate action. Important decisions about students should not be made on the basis of these examinations in their current form.

Maintenance and administration of the BSET require a commitment of resources and time at the state and institutional level. This study does not support such expenditures since the BSET does not appear to have had a positive impact on student achievement or the remedial programs.

\section{Recommendations}

Based on the results of this study, the following actions are recommended:

1. Further analysis of the psychometric properties of the BSET should be 
conducted at M-DCC before any additional students are denied access to college-level courses based on their BSET score.

2. If the reliability of the BSET can not be increased to acceptable levels following the blueprints and using items prepared by the State, M-DCC needs to raise this issue through the appropriate channel: The Statewide Council of Instructional Affairs.

3. M-DCC should argue, through appropriate State-level committees, for the use of existing State Accountability Measures to monitor the quality and effectiveness of remedial programs in the Community Colleges.

Given that important decisions about students are being made on the basis of BSET scores, and that reliability estimates obtained for the BSET examinations are unacceptably low, Miami-Dade Community College needs to conduct further analysis of the tests as soon as possible. The study should include an item analysis to identify items that are poorly worded, possibly keyed incorrectly in the item bank, or faulty in other ways. Particular attention should be paid to items that appear to be too easy, too difficult, or ineffective in discriminating between better and poorer performing students. The analysis should also include a study of test-retest reliability to corroborate or refute the reliability estimates obtained in the course of this study. Administration procedures across campuses and academic departments also need to be reviewed to ensure consistency. Steps must be taken to improve the reliability and validity of the examinations in order to justify their use in decisions about student progress.

The State of Florida mandates that community colleges use the test blueprints and items from the item bank, if not the prepared test forms. If it is determined that the 
reliability of the BSET cannot be improved to acceptable levels within these parameters, this information must be communicated to the Student Assessment Services Section of the Florida Department of Education. Working through the Statewide Council of Instructional Affairs, M-DCC should recommend that a state level analysis of BSET reliability and validity be conducted. Given the lack of impact on subsequent course performance observed in the current study, the utility of the BSET needs to be established at the state level if the mandate to continue using the test remains in effect. The results of the current study indicate that important decisions about students should not be made on the basis of BSET results. If state-level studies reach similar conclusions, the BSET should be abandoned as a state-mandated high-stakes test. Rather, institutions should be empowered to develop their own defensible criteria for assigning grades to remedial students.

A number of state and institution level measures of accountability are already collected and reported to discourage grade inflation and act as quality control checks. These measures include retention and success rates for students who begin in remedial instruction compared to college-ready students; CLAST performance at 60 credits for remedial completers compared to college-ready students; number of Associate in Arts graduates who began in remedial coursework; performance in upper division coursework in the State University System for students who transfer with the Associate in Arts degree; and job placement rates for Associate in Science degree students. Greater emphasis should be placed on these State Accountability Measures, perhaps with incentive funding for maintaining high levels of performance. Of the measures listed above, performance based funding is currently provided for the number of Associate in 
Arts graduates who began in remediation, and completion and placement rates for Associate in Science degree students (Florida Community College System, 2001). In addition to the measures listed above, incentive funding is allocated for the number and percent of students who successfully complete required remediation. This measure balances the measures that assess performance of remedial students in meeting the CLAST requirement and completing the A.A. degree, so that institutions do not inflate their results on these performance measures by unduly restricting students' progress in remediation.

To ensure that the State Accountability Measures are effective in influencing educational outcomes as described above, incentive funding should be applied to additional Accountability Measures. For example, the performance of A.A. transfers to the State University System is reported but not rewarded by incentive funding. More widespread and public reporting of Accountability Measures is also needed to reassure policy makers that colleges are performing up to standards. These steps should eliminate the need for such reassurance to come from a high-stakes test that may be counterproductive to the goals of quality and access.

Community colleges are accountable to the state for providing high quality education, and for ensuring that high and consistent standards are in place to measure and attest to student learning. Perhaps more importantly, community colleges are accountable to the students for ensuring that they are given a fair grade that reflects their attainment of stated educational objectives, and that a passing grade means the student is well prepared for the next course, educational experience, or employment challenge. Community colleges are also accountable to the communities they serve to ensure that graduates have 
consistently high levels of knowledge, skills and abilities to meet the demands of further education or employment. Students and the community as a whole should feel confident that a community college degree guarantees that students have attained such knowledge, skills and abilities. State Accountability Measures and students' ability to choose educational providers ensure that these community college responsibilities are met. 
Airasian, P. W., \& Madaus, G. F. (1983). Linking testing and instruction: Policy issues. Journal of Educational Measurement, 20(2), 103-118.

Bashford, J. (1998). College preparatory exit test results for 97-2 (Institutional Research Note 6-17-1998). Miami, FL: Miami-Dade Community College, Institutional Research.

Bishop, J. (1998). Do Curriculum-Based External Exit Exam Systems enhance student achievement? CPRE Research Report Series RR-40. Philadelphia, PA: University of Pennsylvania, Consortium for Policy Research in Education.

Black, P. J. (1998). Testing: Friend or foe? The theory and practice of assessment and testing. Washington, D.C.: The Falmer Press.

Cizek, G. J. (2001). More unintended consequences of high-stakes testing. Educational Measurement: Issues \& Practice, 20(4), 19-27.

Coleman, A. L. (June, 2000). Fair testing: How schools should protect students' rights in high-stakes testing. American School Board Journal, 32-35.

College Board (1993). Accuplacer users guide: CPTs technical data supplement. Princeton, NJ: Author.

College Level Academic Skills Project. (1983). CLAST technical report 1982-83. Tallahassee, FL: State of Florida Department of Education.

Common Placement Testing for Public Postsecondary Education. 16 F.S. 240.117 (4)(a). F.S. Retrieved October 20, 2002, from http://www.leg.state.fl.us/statutes/index.

Division of Community Colleges (2001). The fact book (Report for the Florida Community College System). Tallahassee, FL: Florida Department of Education.

Dunne, D. W. (2000). Are high-stakes tests punishing some students? Education World. Retrieved May 5, 2002, from http://www.educationworld.com/a_issues/issues093.shtml.

Einspruch, E. (1988). An examination of selection bias in the Florida College Level Academic Skills Test: A summary of the author's dissertation (Institutional Research Information Capsule No. 88-06C). Miami, FL: Miami-Dade Community College, Institutional Research.

Ewell, P. (2001). Statewide testing in higher education. Change, 33(2), 21-27. 
Florida Community College System (2000). Accountability reports 2000. Tallahassee, FL: Author.

Florida Community College System (2001). 2001-2002 Legislative summary financial affairs briefing package. Tallahassee, FL: Bureau of Financial and Business Services.

Florida Department of Education. Florida's Comprehensive Assessment Test (FCAT) home page. Retrieved December 1, 2001, from http://www.firn.edu/doe/sas/fcat.htm.

Florida Department of Education (2002). Readiness for college: Performance of 19992000 Florida public high school graduates on entry-level college placement tests in the 2000-2001 academic year. Tallahassee, FL: Author.

Frederiksen, N., Mislevy, R. J., \& Bejar, I. I. (Eds.) (1993). Test theory for a new generation of tests. Hillsdale, N.J.: Lawrence Erlbaum Associates.

Garcia, R. (1995). The reliability and predictive validity of the College Level Academic Skills Test for Miami-Dade Community College students. Unpublished doctoral dissertation, University of Miami, Miami.

Glaser. R., \& Silver, E. (1994). Assessment, testing, and instruction: Retrospect and prospect. Review of Research in Education, 20, 393-419.

Griffin, B.W., \& Heindorn, M.H. (1996). An examination of the relationship between minimum competency test performance and dropping out of high school. Educational Evaluation and Policy Analysis, 18, 243-252.

Haertel, E. H. (1999, Winter). Validity arguments for high stakes testing: In search of the evidence. Educational Measurement: Issues and Practice, 18(4), 5-9.

Haney, W., \& Madaus, G. E. (1986). Effects of standardized testing and the future of the National Assessment of Educational Progress. Massachusetts: Working Paper for the NAEP Study Group. (ERIC Document Reproduction Service No. ED 279 680)

Heubert, J.P., \& Hauser, R.M. (1999). High stakes: Testing for tracking, promotion, and graduation. Washington, DC: National Academy Press.

Institutional Research. (2002). Demographics, fall 2001. Retrieved July 1, 2002 from Miami-Dade Community College, Institutional Research web site: http://www.mdcc.edu/mdcc/ir. 
Kane, M. (2002). Validating high-stakes testing programs. Educational Measurement: Issues and Practice, 21(1), 31-41.

Klein, S.P., Hamilton, L.S., McCaffrey, D.F., \& Stecher, B.M. (2000). What do test scores in Texas tell us? Rand Education Issue Paper 202. (Available on-line http://www.rand.org/publications/IP/IP202)

Kohn, A. (2000). Burnt at the high stakes. Journal of Teacher Education, 51(4), 315-327.

Leithwood, K., \& Earl, L. (2000). Educational accountability effects: An international perspective. Peabody Journal of Education, 75(4), 1-18.

Lewis, A. (2000, April). High stakes testing: Trends and issues (Policy Brief). Colorado: Mid-Continent Research for Education and Learning. (ERIC Document Reproduction Service No. ED 442 806).

Linn, D. (1998). High school exit exams: Setting high expectations. Retrieved May 11, 2002, from NGA Center for Best Practices, Education Policy Studies web site: http://www.nga.org/center/divisions/1\%2C1188\%2CC ISSUE_BRIEF^D_1478 $\% 2 \mathrm{C} 00 . \mathrm{html}$.

Linn, R. L. (2000). Assessments and accountability. Educational Researcher, 20(2), 4-16.

Losak, J. (1992). CLAST - A final look (Institutional Research Report No. 92-09R). Miami, FL: Miami-Dade Community College, Institutional Research.

Losak, J. \& Einspruch, E. (1989). An examination of issues related to the 1989 CLAST standards. Miami, FL: Miami-Dade Community College.

Madaus, G. F., \& Kellaghan, T. (1993). Testing as a mechanism of public policy: A brief history and description. Measurement and Evaluation in Counseling and Development, 26, 6-10.

Marion, S.F., \& Sheinker, A. (1999). Issues and consequences for state-level minimum competency testing programs. National Center on Educational Outcomes.

(Available on-line http://www.coled.umn.edu/NCEO/OnlinePubs/WyReport1.html)

Maxey, J. (1986). Relationships among ACT assessment scores and CLAST for students tested with College-Level Academic Skills Tests between March 1984 and October 1985. Iowa City, IA: American College Testing Program.

McTarnaghan, R. E. (1987). The impact of assessment on minority access. New Directions for Community Colleges, 59, 75-82. 
McTarnaghan, R. E. (1990). The effects of assessment on minority participation and achievement in higher education. New Directions for Institutional Research, 65, 77-84.

Morris, C., \& Belcher, M. (1990). What factors predict differences in CLAST performance among community colleges (Institutional Research Report No. 9012R). Miami, FL: Miami-Dade Community College, Institutional Research.

The National Center for Postsecondary Improvement (1998). Tracking a subtle storm: Assessment policies in higher education. [Available on-line http://www.stanford.edu/group/ncpi/documents/pdf/lndma98.pdf]

Natriello, G. \& Pallas, A.M. (November, 1998). The development and impact of high stakes testing. Retrieved May 11, 2002, from http://www.columbia.edu/ gin6/histake.html.

Nitko, A. J. (1983). Educational tests and measurement: An introduction. New York: Harcourt Brace Jovanovich, Inc.

Nunnally, J. (1978). Psychometric Theory. New York: McGraw-Hill.

Phillips, S.E. (2000). GI Forum v. Texas Education Agency: Psychometric evidence. Applied Measurement in Education, 13(4), 343-385.

Prus, J., \& Johnson, R. (1994, Winter). A critical review of student assessment options. New Directions for Community Colleges, 22(4), 69-83.

Rodriguez, S. (2000). College Preparatory Exit Test Results for 1999-1 (Research Note August 8, 2000). Miami, FL: Miami-Dade Community College, Institutional Research.

Schafer, W. D. (2000). GI Forum v. Texas Education Agency: Observations for states. Applied Measurement in Education, 13(4), 411-418.

Shepard, L. A. (1991). Psychometricians' beliefs about learning. Educational Researcher, 20 (6), 2-16.

Shepard, L.A. (2000). The role of assessment in a learning culture. Presidential Address to the 2000 Annual Meeting of the American Educational Research Association. [Available on-line http://www.aera.net/meeting/am2000/wrap/praddr06.htm].

Staff of the Committee on Higher Education. (1996). A review of remedial student progress at community colleges. Tallahassee, FL: Committee on Higher Education, Florida Senate. 
State Level Panel. (1984). Report of the state level panel for CLAST standards to Commissioner Ralph Turlington. Tallahassee, FL: Author.

Ward, C. A. (2000). GI Forum v. Texas Education Agency: Implications for state assessment programs. Applied Measurement in Education, 13(4), 419-426.

Winfield, L. F. (1990). School competency testing reforms and student achievement: exploring a national perspective. Education Evaluation and Policy Analysis, 12, 157-73.

Wright, T. J. (1992). A study of the effects of Florida's college-level academic standards on student performance at a selected community college. Unpublished doctoral dissertation, Florida International University, Miami. 


\section{APPENDICES}




\section{APPENDIX A \\ WRITING TEST \\ Florida College Basic Skills Exit Test \\ 1999 Test Blueprint}

The writing section of the Florida College Basic Skills Exit test consists of two parts, both of which are mandatory.

Part A consists of a minimum of 40 multiple-choice items from the state-developed item bank. An institution can create alternate forms of the test but must use items from the state-developed item bank and must follow the blueprint. An institution can create a longer test using the specified percentage of items for each of the competencies shown below. Additional items must come from the state-developed item bank.

Part B consists of a fully developed, unified, and coherent paragraph or short essay. The institution will create the test booklets for Part B, using the sample test directions found in the item specifications. Each test form for the writing segment will contain one abstract prompt and one concrete prompt from the statedeveloped item bank. The scoring rubric appears in the item specifications.

\begin{tabular}{|l|l|c|c|}
\hline & COMPETENCIES AND SKIIIS & $\begin{array}{c}\% \mathrm{mc} \\
\text { items }\end{array}$ & $\begin{array}{c}\text { \# mc } \\
\text { items }\end{array}$ \\
\hline 1. & Conceptual and Organizational Skills & $25 \%$ & 10 \\
\hline 1.1 & identifies a topic sentence or a thesis statement & & 2 \\
\hline 1.2 & $\begin{array}{l}\text { recognizes adequate support provided by generalized and specific } \\
\text { evidence }\end{array}$ & & 2 \\
\hline 1.3 & arranges ideas and supporting details in a logical pattern & & 2 \\
\hline 1.4 & $\begin{array}{l}\text { identifies supporting material that is relevant or irrelevant to the topic } \\
\text { sentence or thesis statement }\end{array}$ & & 2 \\
\hline 1.5 & recognizes effective transitional devices within the context of a passage & & 2 \\
\hline 2. & Word Choice Skills & $10 \%$ & 4 \\
\hline 2.1 & chooses the appropriate word or expression in context & & 2 \\
\hline 2.2 & recognizes commonly confused or misused words or phrases & & 2 \\
\hline 3. & Sentence Structure Skills & $25 \%$ & 10 \\
\hline 3.1 & places modifiers correctly & & 2 \\
\hline 3.2 & uses coordination and subordination effectively & & 2 \\
\hline 3.3 & recognizes parallel structure & & 2 \\
\hline 3.4 & avoids fragments, comma splices, and fused sentences & & 4 \\
\hline 4. & Grammar, Spelling, Capitalization, and Punctuation Skills & $40 \%$ & 16 \\
\hline 4.1 & uses standard verb forms & & 1 \\
\hline 4.2 & avoids inappropriate shifts in verb tense & & 2 \\
\hline 4.3 & maintains agreement between subject and verb & & 2 \\
\hline 4.4 & maintains agreement between pronoun and antecedent & & 1 \\
\hline 4.5 & avoids inappropriate pronoun shifts & & 2 \\
\hline 4.6 & maintains clear pronoun references & & 1 \\
\hline 4.7 & uses proper case forms & & 1 \\
\hline 4.8 & uses adjectives and adverbs correctly & & 1 \\
\hline 4.9 & uses appropriate degree forms & & 1 \\
\hline 4.10 & uses standard spelling & & 1 \\
\hline 4.11 & uses standard punctuation & & 2 \\
\hline 4.12 & uses standard capitalization & & 1 \\
\hline & & & \\
\hline
\end{tabular}




\section{READING TEST \\ Florida College Basic Skills Exit Test \\ 1999 Test Blueprint}

The Reading test consists a minimum of 36 multiple-choice items from the state-developed item bank An institution can create alternate forms of the test but must use items from the state-developed item bank and must follow the blueprint. An institution can create a longer test using the specified percentage of items for each of the competencies shown below. Additional items must come from the state-developed item bank.

\begin{tabular}{|l|l|c|c|}
\hline & COMPETENCIES AND SKIILLS & $\begin{array}{c}\% \mathrm{mc} \\
\text { items }\end{array}$ & $\begin{array}{c}\text { \# mc } \\
\text { items }\end{array}$ \\
\hline 1. & Author's Message & $34 \%$ & 12 \\
\hline 1.1 & determines main ideas & & 4 \\
\hline 1.2 & recognizes supporting details & & 4 \\
\hline 1.3 & determines the author's purpose & & 4 \\
\hline 2. & Structural Relationships & $22 \%$ & 8 \\
\hline 2.1 & identifies organizational patterns & & $2-3$ \\
\hline 2.2 & recognizes relationships within a sentence & & $2-3$ \\
\hline 2.3 & recognizes relationships between sentences & & $2-3$ \\
\hline 3. & Language & $22 \%$ & 8 \\
\hline 3.1 & determines the meaning of words or phrases in context & & $2-3$ \\
\hline 3.2 & detects bias & & $2-3$ \\
\hline 3.3 & recognizes tone & & $2-3$ \\
\hline 4. & Reasoning & $22 \%$ & 8 \\
\hline 4.1 & distinguishes between fact and opinion & & $2-3$ \\
\hline 4.2 & draws logical inferences and conclusions & & $2-3$ \\
\hline 4.3 & evaluates reasoning & & $2-3$ \\
\hline
\end{tabular}




\section{MATHEMATICS TEST \\ Florida College Basic Skills Exit Test \\ 1999 Test Blueprint}

The Mathematics test consists of a minimum of 30 multiple-choice items from the state-developed item bank. An institution can create alternate forms of the test but must use items from the state-developed item bank and must follow the blueprint. An institution can create a longer test using the specified percentage of items for each of the competencies shown below. Additional items must come from the state-developed item bank.

\begin{tabular}{|c|c|c|c|}
\hline & COMPETENCES AND SKULLS & $\begin{array}{l}\% \text { mc } \\
\text { items }\end{array}$ & $\begin{array}{l}\text { \# mc } \\
\text { items }\end{array}$ \\
\hline 1. & Real Number System & $10 \%$ & 3 \\
\hline 1.1 & applies the order-of-operations to expressions & & $\| I I I I I I I I I$ \\
\hline 1.1 .1 & $\begin{array}{l}\text { applies the order-of-operations to expressions without grouping symbols } \\
\text { or exponents }\end{array}$ & & 1 \\
\hline 1.1 .2 & $\begin{array}{l}\text { applies the order-of-operations to expressions with parentheses and } \\
\text { exponents }\end{array}$ & & 1 \\
\hline 1.2 & simplifies sums and differences of absolute values & & 1 \\
\hline 2. & Linear Equations and Inequalities & $30 \%$ & 9 \\
\hline 2.1 & simplifies algebraic expressions & & 1 \\
\hline 2.2 & evaluates aigebraic expressions & & 1 \\
\hline 2.3 & solves linear equations in one variable & & 2 \\
\hline 2.4 & solves literal equations & & 1 \\
\hline 2.5 & solves linear inequalities in one variable & & 1 \\
\hline 2.6 & translates and solves word problems & & \\
\hline 2.6 .1 & translates word problems & & 1 \\
\hline 2.6 .2 & solves word problems & & 1 \\
\hline 2.6 .3 & translates word problems into proportions & & 1 \\
\hline 3. & Exponents & $13 \%$ & 4 \\
\hline 3.1 & simplifies exponential expressions & & IIIIIIIIIIII \\
\hline 3.1 .1 & simplifies an exponential expression with positive integer exponents & & 1 \\
\hline 3.1 .2 & simplifies an exponential expression with negative integer exponents & & 1 \\
\hline 3.1 .3 & $\begin{array}{l}\text { simplifies an exponential expression with integer exponents to include } \\
\text { zero as an exponent }\end{array}$ & & 1 \\
\hline 3.2 & uses scientific notation & & 1 \\
\hline 4. & Polynomials & $10 \%$ & 3 \\
\hline 4.1 & adds/subtracts polynomials & & 1 \\
\hline 4.2 & multiplies a monomial by a binomial & & 1 \\
\hline 4.3 & multiplies two binomials & & 1 \\
\hline 5. & Factoring & $23 \%$ & 7 \\
\hline 5.1 & factors polynomials & & IIIIIIIIIIII \\
\hline 5.1 .1 & factors the greatest common factor & & 1 \\
\hline 5.1 .2 & factors the difference of two squares & & 1 \\
\hline 5.1 .3 & factors polynomials by grouping & & 1 \\
\hline 5.1 .4 & factors trinomials & & 1 \\
\hline 5.2 & simplifies rational expressions & & 1 \\
\hline 5.3 & solves quadratic equations by factoring & & 2 \\
\hline 6. & Radicals (Square Roots Only) & $7 \%$ & 2 \\
\hline 6.1 & simplifies square roots of monomials & & 1 \\
\hline 6.2 & adds, subtracts, or multiplies square roots of monomials & & 1 \\
\hline 7. & Graphing & $7 \%$ & 2 \\
\hline 7.1 & identifies the intercepts of a linear equation & & 1 \\
\hline 7.2 & matches given linear equations to their graphs & & 1 \\
\hline
\end{tabular}




\section{FLORIDA DEPARTMENT OF EDUCATION}

May 28, 20001

MEMORANDUM

TO:

Academic Vico Presidents and Deans

Cormmunity Colleges and Florida A \& M University

FROM: $\quad$ Thomas H. Fisher, Administrator

Assessment and Evaluation Services

Connie Graunke, Director of Articulation and Student Services

Division of Community Colleges

SUBJECT: Materials for the Florida College Basic Skills Exit Test

Through Section 240.117 (4)(a), F.S., the 1997 Legislature made passing an exit test a condition for meeting basic college computation and communication skills requirements. As a service to the institutions offering college preparatory programs, the Departonent of Education has developed tests and related materials to meet the requirements of the legislation. Those materials accompany this memorandum.

According to law, students must pass both the college preparatory coursework and an Exit Test. As determined by the Council on Instructional Affairs, all Florida community colleges and Florida A \& M University are required to administer the Florida College Basic Skills Exit Test as of the fall semester of 1999. The Exit Test is to be sdministered following the completion of the highest level of college preparatory coursework and prior to enrollment in collego credit English or mathematics courses that apply toward degree requirements. Students enrolled in ESL courses may take the Exit Test. Students who have completed remediation through a private provider should take the Florida College Entry-Level Placement Test (for the purpose of determining placement in college-level coursework) instead of the Exit Test.

Institutions may use the test forms provided by the State and/or they may develop their own tests following the enclosed blueprints and using only items from the state-developed item bank. Institutions may alter the order of the test items on test forms that they create, but they may not alter the wording or the content of the test items.

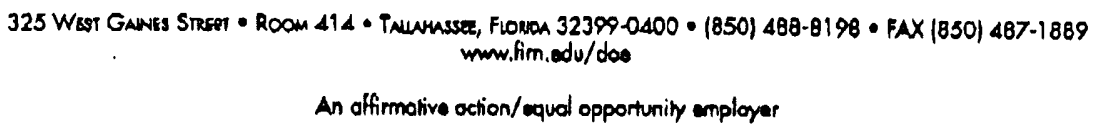


May 28, 2001

Page Two

Institutions trust treat these test items in a secure manner, they are a common resource and must be protected.

The enclosed item banks and test forms $\mathrm{G}$ and $\mathrm{H}$ are intended to augment the item banks and test forms $C$ and D issued to the institutions in May 1999 and forms $E$ and F issued in May 2000. The May 1999 and May 2000 item banks and test forms C, D, E, and F must remain secure.

Institutions may continue to use the item banks and test forms $A$ and $B$ issued by the Department in December 1997. Institutions may use the items on practice tests, or if the items have remained secure, on tests that the institution may develop, following the current state-developed blueprint. Items used on practice tests may not bo used on the actual Exit Test administered to determine a student's pase/fail status.

The enclosed test blueprints have been approved by the Council on Instructional Affairs, who also approved the following guidelines for use of these tests and the item banks.

Each institution will be responsible for

- maintaining test security

- determining when to administer the test

- administering the test

- identifying range finders for the writing sample (Part $B$ of the Writing subtest)

- training readers for the writing sample (Part B of the Writing subtest)

- sooring the test

- establishing retest policy

- setting passing requirements for the test

- setting passing requirements for the college preparatory courso

Except as noted in the next paragraph, examinees are not permitted to use calculators on the Mathematics subtest or dictionaries or other reference materials on the Reading and Writing subtests. Examinees may write their essays on computers, but may not use spell checkers or other aids.

Institutions are responsible for determining whether examinees meet the criteria for waivers or for accommodations for disabilities. Only students who have diagnosed learning disabilities and dooumented authorization to use a calculator in mathematics coursework may use a calculator on the Mathematics subtest. Institutions determine the length of the test administration time.

The Florida College Basic Skills Exit Test includes three subtests: Mathematics, Reading, and Writing. The following materials ate provided for each subtest. Please note that certain materials are secure and must be maintained in a secure manner. 
May 28, 2001

Page Three

The following materials are contained in each of the three large manila envelopes labeled "Mathematics," "Reading," and "Writing."

1. A document labeled "Test Item Bank"

The test blueprint is included in this envelope. The item banks are Secure.

2. A smaller envelope containing single copies of the test forms, Item map, and disk The tests forms, item maps, and dioks are Secure.

Please note that if your institution chooses to print the test forms from the disks, you may have to reformat because of the differences in word processing programs and in printers. If your institution chooses to create its own test forms using the item banks provided on the disks, you will need to creato your own test format. Consult your local computer technical assistance personnel if you have questions concerning converting and/or formatting.

Please see the attachments for further explanations of the contents and directions on how to use these materials.

If you have any questions about the Florida College Basic Skills Exit Test, please call Kathy Fearon or Ken Loewe at (850) 488-8198.

cc: Don Griesheimer
Tom Furlong

TF/ld

Attachments 
JOANNE BASHFORD

Born, Pittsburgh, Pennsylvania, USA

1981

B.A., Psychology

University of Florida

Gainesville, Florida

1986

M.Ed., Counselor Education

University of Pittsburgh

Pittsburgh, Pennsylvania

1987-1989

Adjunct Trainer/Facilitator

University of Pittsburgh

Pittsburgh, Pennsylvania

1986-1990

Career Counselor

Career Assessment Center, Inc.

Butler, Pennsylvania

1990-1992

Personnel Administrator, Examination Section

City of Pittsburgh

Pittsburgh, Pennsylvania

1992-1995

Director of Testing, Kendall Campus

Miami-Dade Community College

Miami, Florida

1995-1998

District Director of Test Administration and Program Evaluation Miami-Dade Community College

Miami, Florida

1998-Present

Associate Director of Institutional Research

Miami-Dade Community College

Miami, Florida

PUBLICATIONS AND PRESENTATIONS

Bashford, J. (2000). Associate in Arts student follow-up: Transfer destinations of 1996-97 A.A. completers and leavers (Institutional Research Information Capsule No. 2000-11C). Miami, FL: Miami-Dade Community College, Institutional Research. 
Bashford, J. (2001). Enrolled student evaluation of Miami-Dade Community College services 2000 (Institutional Research Report No.2001-02R). Miami, FL: MiamiDade Community College, Institutional Research.

Bashford, J. (2001). The impact of PASS (practice CPT) testing on CPT scores (Institutional Research Information Capsule No. 2001-03C). Miami, FL: MiamiDade Community College, Institutional Research.

Bashford, J. (2001). Performance based budgeting comparison: 2000-01 and 2001-02 allocations (Institutional Research Information Capsule No. 2001-04C). Miami, FL: Miami-Dade Community College, Institutional Research.

Bashford, J. (2001). Report on users' satisfaction with services provided by Institutional Research (Institutional Research Report No.2001-04R). Miami, FL: Miami-Dade Community College, Institutional Research.

Bashford, J. (2002). Tracking M-DCC Associate in Arts graduates, 1998-99 (Institutional Research Information Capsule No. 2002-03C). Miami, FL: Miami-Dade Community College, Institutional Research.

Bashford, J. (2002). Using PASS to enhance placement decisions (Institutional Research Information Capsule No. 2002-04C). Miami, FL: Miami-Dade Community College, Institutional Research.

Bashford, J. (2002). Reading course progression (Institutional Research Information Capsule No. 2002-08C). Miami, FL: Miami-Dade Community College, Institutional Research.

Bashford, J. (2002). English course progression (Institutional Research Information Capsule No. 2002-09C). Miami, FL: Miami-Dade Community College, Institutional Research.

Bashford, J. (2002). Mathematics course progression (Institutional Research Information Capsule No. 2002-11C). Miami, FL: Miami-Dade Community College, Institutional Research.

Bashford, J. (2002, April). The use of practice placement tests to enhance college readiness and placement decisions. Paper presented at the 2002 Annual Meeting of the American Educational Research Association, New Orleans, Louisiana.

Cistone, P. J. and Bashford, J. (2002, Summer). Toward a meaningful institutional effectiveness plan, Planning for Higher Education, 30(4), 15-23. 